Article

\title{
Genes Containing Long Introns Occupy Series of Bands and Interbands in Drosophila melanogaster Polytene Chromosomes
}

\author{
Varvara A. Khoroshko ${ }^{1, *(1)}$, Galina V. Pokholkova ${ }^{1}$, Victor G. Levitsky ${ }^{2,3}$, Tatyana Yu. Zykova ${ }^{1}$, \\ Oksana V. Antonenko ${ }^{1}$, Elena S. Belyaeva ${ }^{1}$ and Igor F. Zhimulev ${ }^{1,3}$ \\ 1 Department of the Chromosome Structure and Function, Laboratory of Molecular Cytogenetics, \\ Institute of Molecular and Cellular Biology SB RAS, 630090 Novosibirsk, Russia; \\ galina@mcb.nsc.ru (G.V.P.); vatolina@mcb.nsc.ru (T.Y.Z.); ovant@mcb.nsc.ru (O.V.A.); \\ belyaeva@mcb.nsc.ru (E.S.B.); zhimulev@mcb.nsc.ru (I.F.Z.) \\ 2 Department of Systems Biology, Laboratory of Evolutionary Bioinformatics and Theoretical Genetics, \\ Institute of Cytology and Genetics SB RAS, 630090 Novosibirsk, Russia; levitsky@bionet.nsc.ru \\ 3 Department of Natural Sciences, Novosibirsk State University, 30090 Novosibirsk, Russia \\ * Correspondence: vicerna@mcb.nsc.ru
}

Received: 22 January 2020; Accepted: 7 April 2020; Published: 11 April 2020

\begin{abstract}
The Drosophila melanogaster polytene chromosomes are the best model for studying the genome organization during interphase. Despite of the long-term studies available on genetic organization of polytene chromosome bands and interbands, little is known regarding long gene location on chromosomes. To analyze it, we used bioinformatic approaches and characterized genome-wide distribution of introns in gene bodies and in different chromatin states, and using fluorescent in situ hybridization we juxtaposed them with the chromosome structures. Short introns up to $2 \mathrm{~kb}$ in length are located in the bodies of housekeeping genes (grey bands or lazurite chromatin). In the group of 70 longest genes in the Drosophila genome, $95 \%$ of total gene length accrues to introns. The mapping of the 15 long genes showed that they could occupy extended sections of polytene chromosomes containing band and interband series, with promoters located in the interband fragments (aquamarine chromatin). Introns (malachite and ruby chromatin) in polytene chromosomes form independent bands, which can contain either both introns and exons or intron material only. Thus, a novel type of the gene arrangement in polytene chromosomes was discovered; peculiarities of such genetic organization are discussed.
\end{abstract}

Keywords: Drosophila melanogaster; polytene chromosomes; bands; interbands; housekeeping genes; chromatin states; gene introns

\section{Introduction}

Studies of the band and interband genetic organization simultaneously began with the discovery of polytene chromosomes in Drosophila in the mid-1930s, and the main hypotheses were soon formulated. For a long time, the detailed structure of genes, their exact chromosome localization, and functional role (developmental or housekeeping) remained unknown.

According to the hypothesis of N. Koltzoff [1], genes are located in the interbands, and bands are inactive chromosome structures, in which crossing over occurs. O. Mackensen [2], H. Muller, and A. Prokofyeva [3] localized the white, vermilion, and scute genes in the chromosome bands, therefore the bands were considered to be gene carriers. Some of the researchers believed that one gene corresponds to one band [2,4]; some supposed that bands could contain different number of genes, which in Drosophila genome could be estimated from five thousand to ten thousand and this roughly complies 
with the number of bands [5,6]. C. Metz believed that the gene could be partly located in the band and partly in the interband [7].

In 1950-1960, genes were localized on chromosomes in the regions using chromosome rearrangements method, the number of which was estimated to be approximately equal to the number of bands [8]. Many researchers assumed that the presence of a single gene in a band can be confirmed by the morphological manifestation of the gene activation in the form of a puff [9-13]. This hypothesis led W. Beermann to conclude that a band on the polytene chromosome is the physical equivalent of the Mendelian gene [14,15]. However, in the mid-1960s, G. Rudkin estimated the average band size to be $30-40 \mathrm{~kb}$, which stipulated that, in one band, there is enough DNA for thirty $1 \mathrm{~kb}$ long genes, thus "one band-one gene" rule is untenable [16]. In connection with these conclusions, hypotheses based on the polygenicity of chromomeres began to appear. Yu. Olenov suggested that groups of genes active in the same tissue are located in bands to explain the obvious redundancy of DNA [17]. At the same time, B. Judd saturated a small region containing thinnest grey bands with mutations; following complementation analysis led the researches to the conclusion that numerical genes and bands ratio in the region is 1:1 [18] (for details see [19]).

In all of the described above gene models interbands played no role; according to the authors, the bands represented independent functional units specifically organized for a single gene or a gene group activity, and the appearance of models that considered the band and the adjoining interband as a single functional unit was unusual. F. Crick [20] believed that most of the DNA coding regions are located in the interbands; according to this hypothesis, the gene regulatory sites are located in the bands. On the contrary, J. Paul [21] and V. Sorsa [22] assumed that the interbands contain the main binding sites for RNA polymerase and, thus, the transcription starts in the interband initiation sites and is directed into bands from there. After the housekeeping genes concept was stated, some researches hypothesized the existence of genes that are active in all cells and they are constantly involved in transcription. Such genes are located in decondensed interbands and developmental genes are located in bands, since the pattern of bands is mostly constant [23,24].

Beginning with C. Bridges, three types of structures were described in polytene chromosomes: interbands and two types of bands-large densely packed black bands and loose light ones that look grey under the light microscope [25-27]. In addition to morphology, the two types of bands differ in the degree of chromatin compaction level, replication time, gene density, the presence or absence of replication origins, the sets of proteins, histone modifications, and chromatin states (see below for details).

After the Drosophila genome sequencing was completed [28] and the modENCODE program (model organism ENCyclopedia Of DNA Elements) identified genome elements [29], various proteins, nucleosomes, replication origins, histones, and their modifications were localized, according to which several chromatin classifications were presented [30-32] (for more details, see [33,34]).

The development of molecular genetic methods of labeling P-element interband insertions helped to determine which types of proteins related to bands and interbands in general [27,35-37]. The 4HMM mathematical model was developed using these data; it revealed four chromatin states that are distinguished by the presence of RNA polymerase II, Origin Recognition Complex (ORC), protein composition, and nucleosome modifications [38-40]. Aquamarine is predominantly localized in the polytene chromosome interbands, contains promoters of housekeeping genes and it is characterized by the specific set of proteins. This state is similar to "YELLOW" and "RED" states in the study of Filion et al. [30] and state "1" (TSS-proximal regions) in the study of Kharchenko et al. [31]. Gene exons along with several proteins and histones characteristic of transcription elongation are located within the lazurite fragments $[33,38,41]$. This state is similar to "YELLOW" state in the study of Filion et al. [30] and state "2" (transcriptional elongation marks) in the study of Kharchenko et al. [31]. Aquamarine and lazurite are both active states, which quite accurately correspond to the areas of open chromatin with condensation level " +1 " in the study of Milon et al. [32]. Malachite always borders ruby fragments on both band edges and seems to be the point of transition between tightly compacted 
band material and decompacted active interband chromatin; this chromatin state was shown to be intermediate in terms of replication timing [42]. This state is similar to "BLACK" and "BLUE" states in the study of Filion et al. [30], state "9" (extensive silent domains) in the study of Kharchenko et al. [31], and it corresponds to neutral chromatin with condensation level " 0 " in the study of Milon et al. [32]. Ruby contains developmental genes and a specific set of proteins characteristic for inactivated chromatin. This state is similar to "BLACK" state in the study of Filion et al. [30], states " 8 " and "9" (heterochromatin-like regions containing moderate levels of H3K9me2/me3 and extensive silent domains) in the study of Kharchenko et al. [31] and corresponds to closed chromatin with condensation level "-1" in the study of Milon et al. [32]. The boundaries of four chromatin states fragments with a certain level of accuracy can be considered to be the boundaries of bands and interbands since each of the chromatin states is quite accurately localized in certain chromosome structures.

Recently, it was showed that interbands in conjunction with two types of bands display the portrait of the functioning genome. The housekeeping genes occupy two chromosome structures: while promoters of these genes are located in the interbands, the adjacent grey bands hold the gene bodies. Developmental genes are located in the dense black bands, which are usually polygenic. It was demonstrated that, in the thinnest bands, DNA is enough predominantly for a single housekeeping gene, so the B. Judd's hypothesis "one gene-one band" was partly confirmed [40].

The length of an average band in Drosophila polytene chromosomes is about $30 \mathrm{~kb}$ according to various estimates [16,43], and the smallest distinguishable band contains $5 \mathrm{~kb}$ of DNA [44], as was already mentioned. When compared with the DNA length in the bands, introns up to $400 \mathrm{~kb}$ are quite large and, therefore, must somehow be detected at the chromosome level; at least, it can be expected that structures that are based on such long introns can be seen under the light microscope, but such data are unavailable in literature. According to our recently obtained preliminary data, certain large genes can occupy extended sections of chromosomes [45,46]. In the present study, we examined the localization sites of the genes that are mentioned above; in addition to that, we picked 12 new regions and analyzed their gene, intron, and chromatin composition, as well as studied their cytological location. We applied a simple approach, by using FISH, we mapped the start and the end of each long gene (usually the longest transcript). Subsequently, we studied the distribution of transcripts, introns, exons, chromatin states, and location of other genes, according to chromosome structures, such as interbands, black and grey bands.

\section{Materials and Methods}

\subsection{Fly Stock}

In the present study, we used the fly stock with mutations in genes white and SuUR ES (Suppressor of Under Replication). The flies were kept on standard cornmeal-yeast-agar-molasses medium and larvae were grown under uncrowded conditions in standard test tubes at $18{ }^{\circ} \mathrm{C}$ for prolonged development [47].

\subsection{Fluorescence In Situ Hybridization}

Salivary glands of third instar larvae were dissected in Ephrussi-Beadle solution and transferred to a small glass cup with a mixture of ethanol and acetic acid (3:1). After 20 min fixation at room temperature, salivary glands were squashed in $45 \%$ acetic acid, frozen in liquid nitrogen, and stored in $70 \%$ ethanol at $-20{ }^{\circ} \mathrm{C}$. Fluorescence in situ hybridization (FISH) on polytene chromosomes was performed as described in [48]. Thirty-five DNA probes were obtained by standard PCR and then labeled with Flu-12-dUTP or Tamra-5-dUTP (Biosan) in random-primed polymerase reaction with the Klenow Fragment. Table S1 lists probes used in this study. Chromosome squashes were analyzed while using epifluorescence optics (Olympus BX50 microscope) and photographed with CCD Olympus DP50. For every probe colocalization, at least 50 nuclei on several slides were analyzed. 


\subsection{Bioinformatic Methods}

In the present study we discuss only protein-coding genes; tRNA are grouped in clusters of $18 \mathrm{~S}$ and $28 \mathrm{~S}$ rRNA and, as a rule, cannot occupy a chromosome region larger than one band or a nuclear organizer [19]. The long non-coding RNA (lncRNA) genes [49] are not considered here because nothing is known regarding their location in polytene chromosome bands or interbands of Drosophila.

Using the full D. melanogaster genome annotation (Release 5.57), we identified transcription and translation start and termination sites for 26,938 transcripts with one or more introns; these data conforms to 11,632 genes. Based on these data, we pinpointed start and end positions for three types of introns, matching with transcripts $5^{\prime}$ - and $3^{\prime}$-untranslated regions (UTR) and the remaining protein-coding sequences (gene bodies). The 5'UTR, gene bodies, and $3^{\prime} \mathrm{UTR}$ sampling groups consisted of 16782, 125,304, and 3125 introns accordingly. For the further analysis, we used the four chromatin-state model (4HMM), which comprises aquamarine (5748), lazurite (4139), malachite (9189), and ruby domains (6025) in the genome of $D$. melanogaster [38,39]. In order to estimate the number of genes when calculating the distribution of genes containing introns in 5'UTR, gene bodies, and 3'UTR by introns coverage with four chromatin states (Figure 1), we determined the equal weights $W$ of introns taking into account the number of introns $N I(T, G)$ of each transcript $T$ of each $G$ gene, as well as the number of transcripts of each $N T(G)$ gene:

$$
W=1 /\{N I(T, G) * N T(G)\},
$$

For the four intron length ranges ( $<2 \mathrm{~kb}, 2-50 \mathrm{~kb}, 50-100 \mathrm{~kb},>100 \mathrm{~kb})$, we estimated the distribution of genes, containing introns in $5^{\prime}$ UTR, gene bodies, $3^{\prime}$ UTR, and overlapped them with four chromatin states (Figure 1). For each intron, the following formula was used:

$$
\text { Number of genes }=K^{*} W *\left(L \_d o m a i n / L \_t o t a l\right) \text {, }
$$

where $K=1$ if the intron hits the length range (otherwise $K=0$ ), $L_{-}$domain equals intron length, which overlaps with the domain of given chromatin state, $L_{-}$total equals the total intron length. We ranked the introns of 5'UTR, gene bodies, and 3'UTR by increasing lengths and determined the dependence of the introns fractions covered by four chromatin states on the intron length to determine the dependence of the introns fractions covered by four chromatin states on length (Figure 2). The calculations were carried out using moving average on the number of introns equaling 500 .

\section{Results}

\subsection{Characteristics of Introns and Genes Located In Different Chromatin Domains In The Drosophila Genome}

Long introns can form bands in polytene chromosomes of Drosophila melanogaster; with this in mind, we studied the distribution and occurrence of genes containing introns, and characteristics of their localization in polytene chromosomes. While using FlyBase Release 5.57, we analyzed length distribution of 13,832 genes and their introns length in the Drosophila genome (Figure 1). With increase in gene length, total gene introns size also increases, as the result the longest genes are almost entirely composed of intron material (Figure 1A). We found that the intron DNA length significantly and positively correlates with the length of genes (Kendall's rank correlation coefficient $r=0.494$, $\mathrm{p}<1 \mathrm{E}^{-973}$ ) (Figure 1A). 


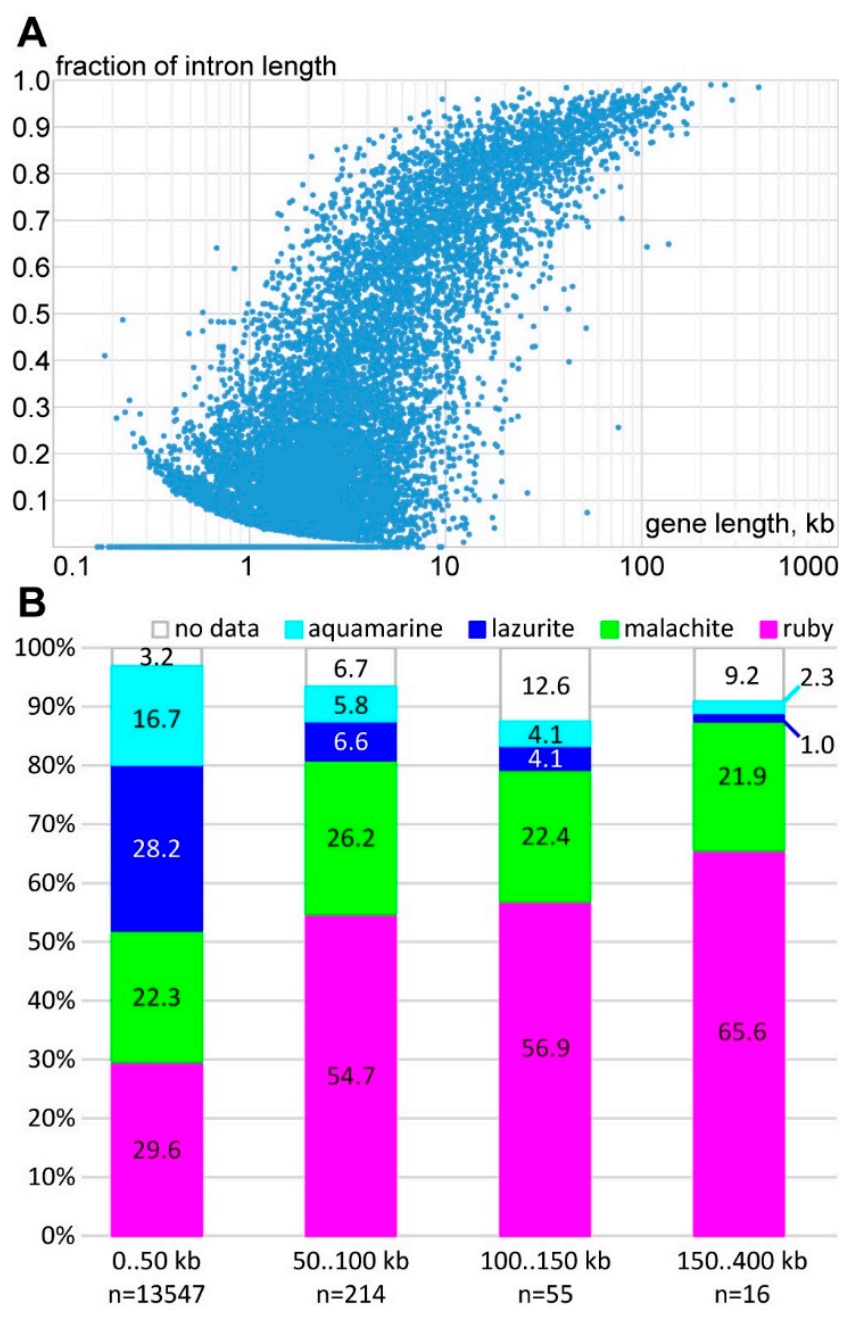

Figure 1. The distribution of introns and different chromatin states according to 4HMM model [39]. (A) fraction of intron length according to the gene length in $\mathrm{kb}$; and, (B) distribution of four chromatin states in genes with length $<2,2-50,50-100$, and $>100 \mathrm{~kb}$ ).

We divided the genes into four groups depending on the length of their largest transcript to relate the data to gene localization in different $4 \mathrm{HMM}$ model chromatin states: lengths up to $50 \mathrm{~kb}, 50-100 \mathrm{~kb}$, 100-150 kb, and over $150 \mathrm{~kb}$. The groups contained 13547, 214, 55, and 16 genes (Figure 1B). We found that, with increasing gene length, the coverage with ruby (known as repressed chromatin in which the developmental genes are located) increases from $30 \%$ for gene lengths up to $50 \mathrm{~kb}$, to $55 \%, 57 \%$, and $66 \%$ for gene lengths in the ranges $50-100 \mathrm{~kb}, 100-150 \mathrm{~kb}$, and over $150 \mathrm{~kb}$, accordingly (Figure 1B). At the same time, the malachite chromatin coverage changes insignificantly $(22 \%, 26 \%, 22 \%$, and $22 \%)$. The active states of chromatin corresponding to interbands and loose bands (promoters and exons of active genes) represent a total of $45 \%$ (17\% and $28 \%$ for aquamarine and lazurite); while, for genes with a longer length, their proportion does not exceed 3\% (Figure 1B). Therefore, the increase of genes length correlates with intron length increase, thus the proportion of repressed chromatin ruby coverage grows, and the proportion of active aquamarine and transcribed lazurite chromatin states reduces.

We analyzed introns within the regions between translation start and termination sites, $5^{\prime}$ - and $3^{\prime}$-untranslated regions in genes located in four chromatin states (Figure 2). The most common gene bodies contain short introns of less than $2 \mathrm{~kb}$ in length, which overlap with lazurite chromatin (3380 genes); less often they overlap with aquamarine (2326 genes) and malachite (1505 gens). Fifty-six genes from this group contain introns, which do not overlap with any chromatin states (Figure 2A). Gene bodies also contain longer introns varying from 2 to $50 \mathrm{~kb}$ in length; however, such genes in 
the Drosophila genome are scarce (418). The introns of this group of genes mainly overlap with ruby (180 genes) and malachite chromatin (88 genes) (Figure 2A). We found only six genes with introns larger than $50 \mathrm{~kb}$, and genes with introns larger than $100 \mathrm{~kb}$ are completely absent (FlyBase). In the Drosophila genome there are 1069 and 243 genes that contain introns of less than $2 \mathrm{~kb}$ in 5'UTR and 3'UTR, as well as 301 and 20 genes that contain introns from 2 to $50 \mathrm{~kb}$ in $5^{\prime} \mathrm{UTR}$ and $3^{\prime} \mathrm{UTR}$, respectively (Figure 2B,C).

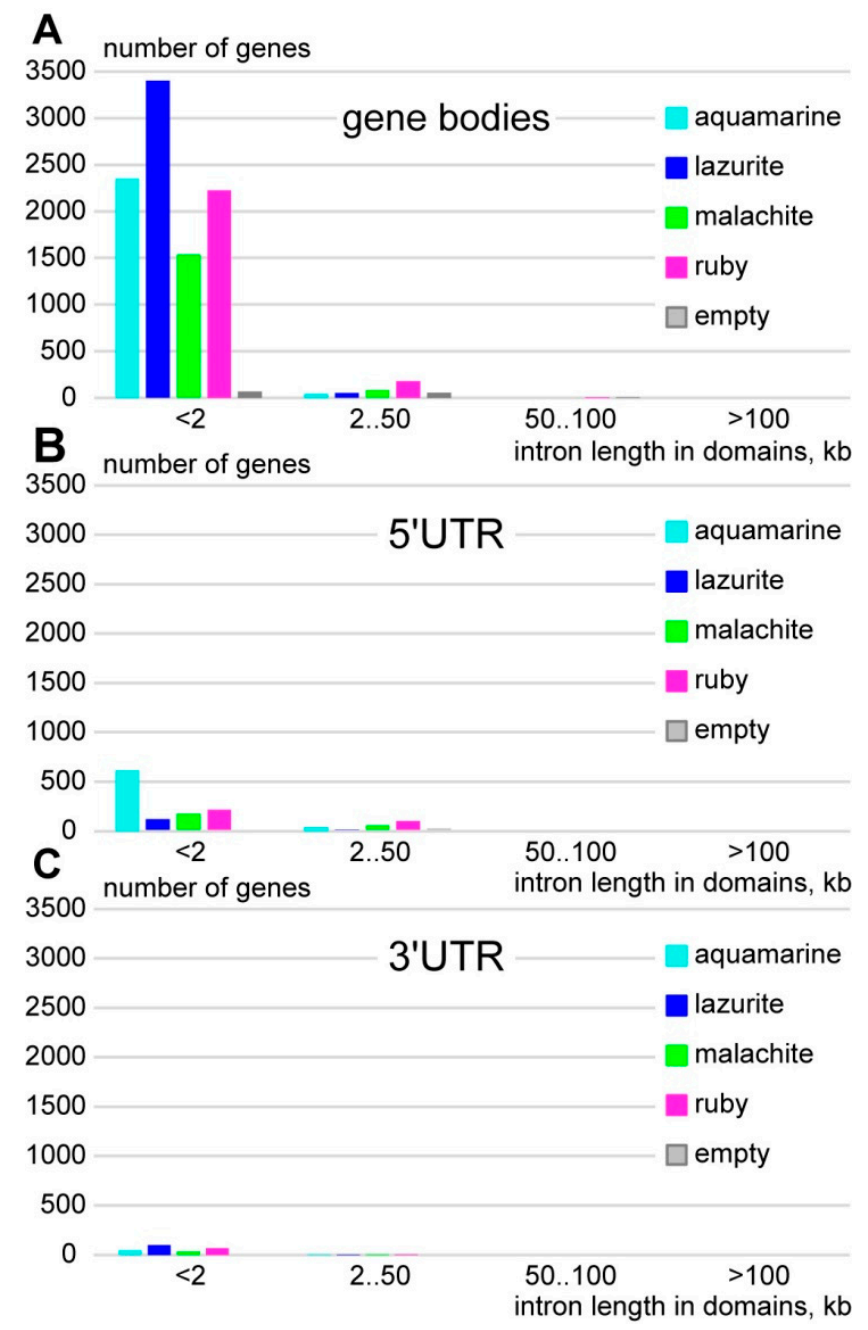

Figure 2. Distribution of the intron fractions and four chromatin states according to gene length in the Drosophila genome. $X$-axis represents gene length (bp); $Y$-axis represents the proportion of introns in the gene; black line represents introns on which $4 \mathrm{HMM}$ model does not provide any data. (A) intron fractions in gene bodies; (B) intron fractions in 5'UTR; and, (C) intron fractions in 3'UTR.

Each intron fragment contains several chromatin states and, with the introns length increase, the proportion of chromatin of various states changes (Figure 3). The size of introns in the gene body varies from 25 to $139,349 \mathrm{bp}$ (mean 1225, median $82 \mathrm{bp}$ ) and it is mainly represented by short introns up to $2 \mathrm{~kb}$ in length, being predominantly enriched in lazurite chromatin. In introns larger than $2 \mathrm{~kb}$, the lazurite fraction decreases and such introns are enriched in ruby and malachite chromatin. Introns that are larger than $5 \mathrm{~kb}$ also include a part of the genome with data being unavailable due to the 4HMM model chromatin states mosaic pattern (Figure 3A). The size of introns in 5'UTR on average vary from 43 to $133,766 \mathrm{bp}$ (mean 4220, median $1120 \mathrm{bp}$ ) and are represented by introns up to $2 \mathrm{~kb}$ in length, mainly enriched in aquamarine chromatin. In introns larger than $2 \mathrm{~kb}$, a decrease in the proportion of aquamarine and enrichment with ruby and malachite chromatin is observed, whereas lazurite chromatin is practically absent in $5^{\prime} \mathrm{UTR}$ of gene introns. Introns that are larger than $6 \mathrm{~kb}$ include a part of genome 
that lacks data for $4 \mathrm{HMM}$ chromatin states (Figure 3B). Introns in 3'UTR vary from 46 to 41,975 bp in length (mean 667, median $88 \mathrm{bp}$ ) and they are enriched in ruby chromatin (Figure 3C).
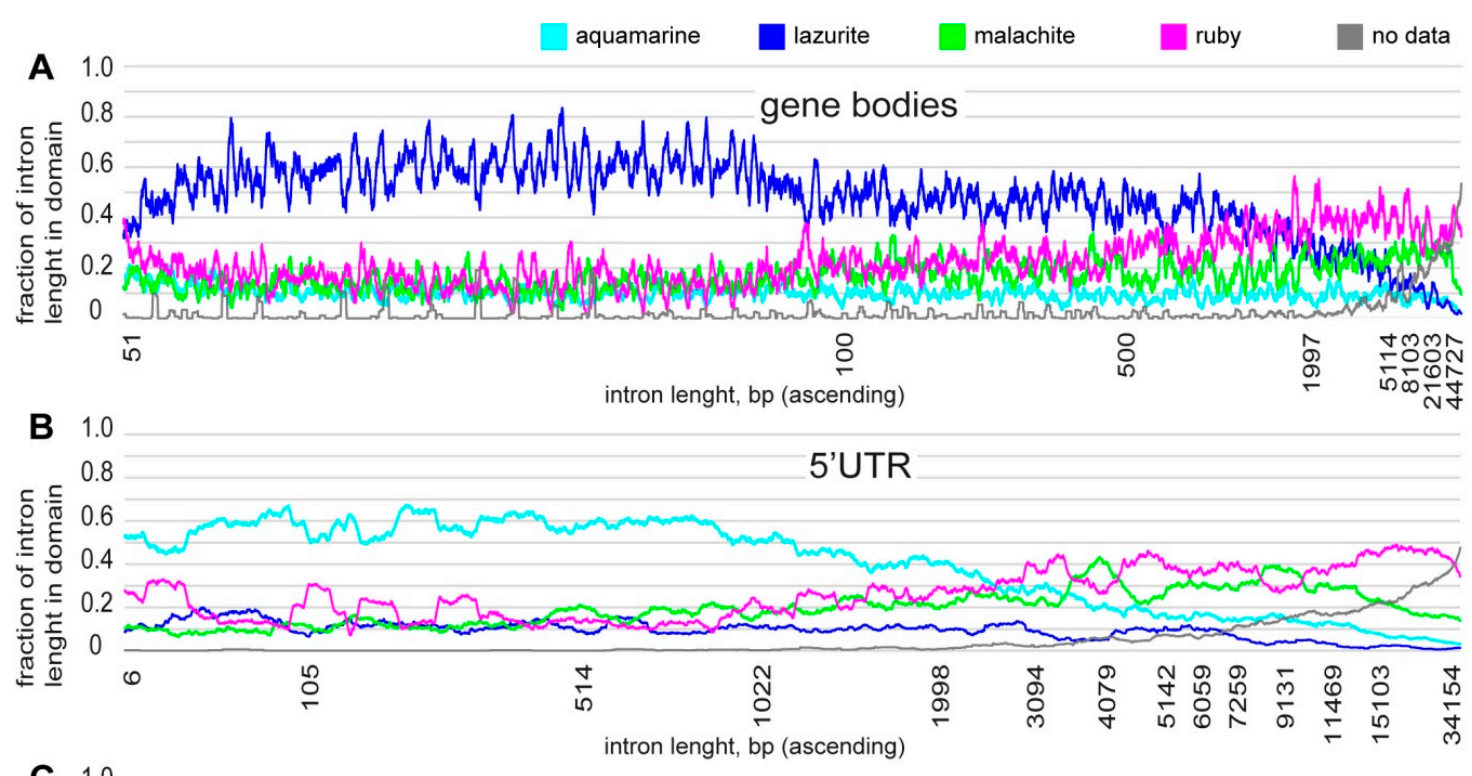

C 1.0

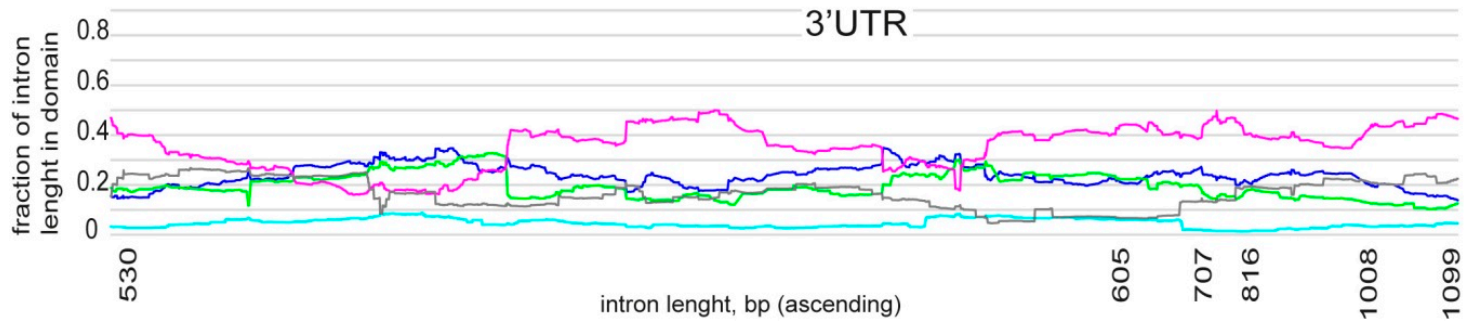

Figure 3. Intron fraction overlapping with four-chromatin states model [39] according to intron length (the calculations were carried out using moving average on the number of introns equaling 500; black line presents genome regions for which data on chromatin states is absent). (A) distribution for gene bodies; (B) distribution for 5'UTR; and, (C) distribution for 3'UTR.

Figure 4 shows the overlap between four chromatin states and the intron coverage in gene bodies, in 5'UTR and 3'UTR. The total length of introns in gene bodies comprises $153.2 \mathrm{Mb}$; aquamarine, lazurite, malachite, and ruby chromatin cover $10.7 \mathrm{Mb}, 23.5 \mathrm{Mb}, 30.8 \mathrm{Mb}$, and $53 \mathrm{Mb}$ respectively. A significant proportion of introns in the gene bodies $(35.5 \mathrm{Mb})$ includes a part of the genome for which data on chromatin states is absent (Figure 4B). Total length of introns in 5'UTR comprises 70.8 $\mathrm{Mb}$; lazurite, malachite, and ruby chromatin cover $2.9 \mathrm{Mb}, 15.6 \mathrm{Mb}$, and $25.9 \mathrm{Mb}$ respectively. For $16.9 \mathrm{Mb}$ of introns in $5^{\prime} \mathrm{UTR}$ data on chromatin states is absent (Figure 4A). The total length of introns in 3'UTR comprises $2.1 \mathrm{Mb}$; aquamarine, malachite, lazurite, and ruby chromatin cover $0.1 \mathrm{Mb}, 0.4 \mathrm{Mb}$, $0.5 \mathrm{Mb}$, and $0.8 \mathrm{Mb}$, respectively. For $0.3 \mathrm{Mb}$ of introns in $3^{\prime} \mathrm{UTR}$ data on chromatin states is absent (Figure 4C). As a result, introns in the gene bodies, in 5'UTR and 3'UTR are mainly represented by ruby and malachite chromatin (developmental genes localization); in gene bodies, introns also overlap with lazurite chromatin. A rather significant proportion of introns corresponds to a part of the genome for which data on 4HMM chromatin states are absent. 


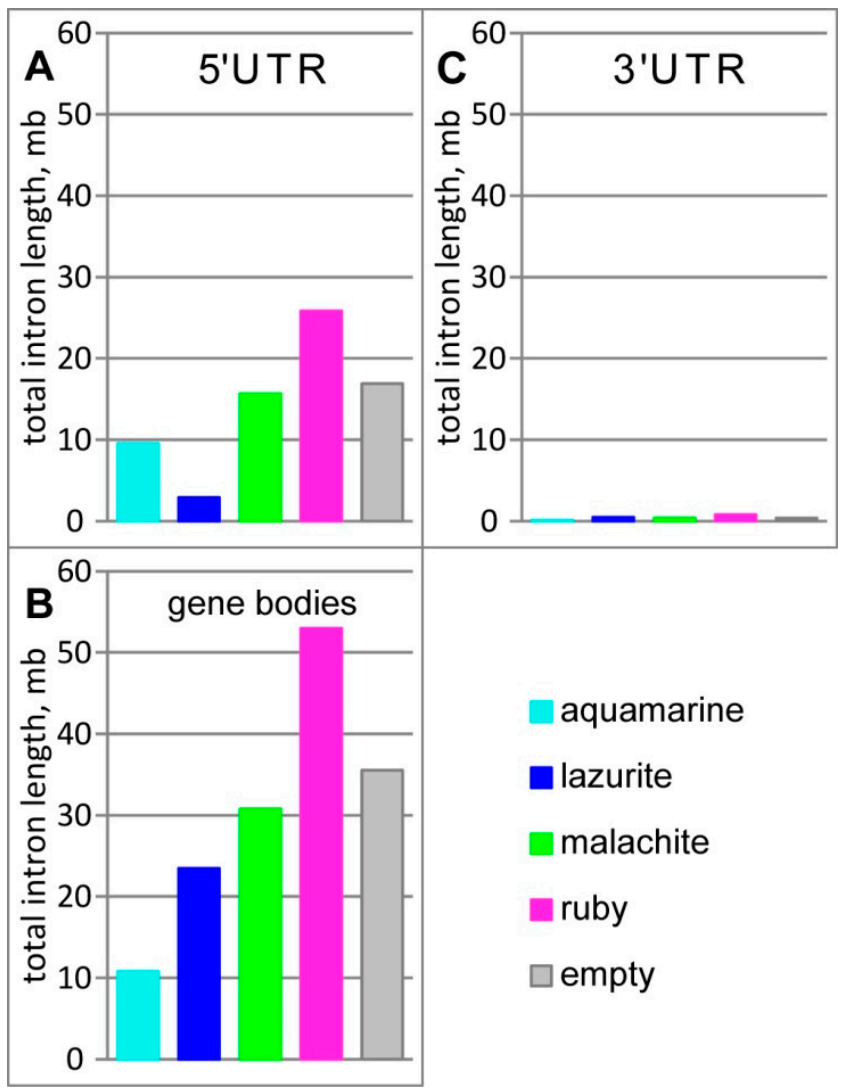

Figure 4. Summed intron length $(\mathrm{Mb})$ overlapping with four-chromatin states model [39]. (A) in 5'UTR; (B) in gene bodies; and, (C) in 3'UTR.

In Drosophila genome, we found 70 genes with length varying from 100 up to $395 \mathrm{~kb}$; the gene intron coverage stand over $95 \%$ for 31 genes, $93 \%$ for $52,90 \%$ for 63 , and $64 \%$ and $60 \%$ for two genes, respectively (Table S2). Thus, the gene length increase relates to the enormous increase of intron length. Figure 5A,B shows the 70 genes overlap with four chromatin states (4HMM) and three chromatin condensation states (3CM). The analysis showed that genes are mostly composed of ruby $(60.1 \%)$ and malachite chromatin (22.1\%). The active chromatin states that correspond to interbands, promoters, and coding fragments of active genes total $6.5 \%$ (aquamarine $3.0 \%$ and lazurite $3.6 \%$ accordingly). For $11.7 \%$ of total gene length, the model does not provide data on chromatin states distribution (Figure 5A). The data on four chromatin states coverage correlate with the result on chromatin compaction level: closed and compact chromatin totals $62.4 \%$, neutral $31.9 \%$, and open active chromatin $5.5 \%$, respectively (Figure 5B). Thus, we can conclude that all 70 studied genes are developmental and localized in black bands.

From the list of 70 genes, we picked three (Table S2) and other 12 developmental genes, which had the longest length and the highest intron coverage, some of which are involved into ecdysone cascade regulation (Table 1). Figure 5C,D show the 15 genes overlap with four chromatin states (4HMM) and three chromatin condensation states (3CM). Introns correspond to malachite chromatin, which covers $41.9 \%$ and inactive state ruby covers $28.2 \%$ of total gene length. Active states corresponding to interbands, promoters and exons of active genes total $22.5 \%$ (aquamarine $12.1 \%$ and lazurite $10.3 \%$, accordingly). For $7.2 \%$ of total gene length, the model does not provide data on chromatin states distribution (Figure 5C). Introns in 15 studied genes mostly overlap with neutral and closed chromatin condensation state and they correspond to $38.8 \%$ and $41.8 \%$ of total gene length accordingly; open chromatin state equals $19.3 \%$ (Figure 5D). 


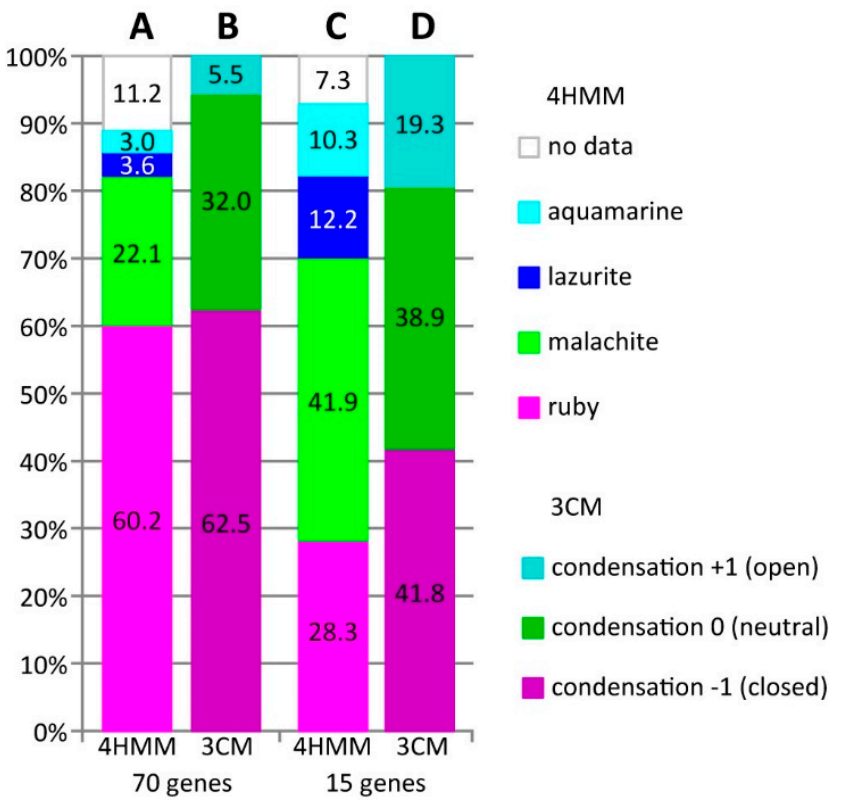

Figure 5. Summed length of four-chromatin states model [39] and three chromatin condensation level model [32] in 70 and 15 studied genes. (A) distribution of chromatin states in 4HMM model in 70 genes (\%); (B) distribution of chromatin condensation states in 3CM model in 70 genes (\%); (C) distribution of chromatin states in 4HMM model in 15 genes (\%); and, (D) distribution of chromatin condensation states in 3CM model in 15 genes (\%).

Table 1. Fifteen long genes characteristics.

\begin{tabular}{|c|c|c|c|}
\hline Gene & $\begin{array}{c}\text { Gene Location } \\
\text { According to UCSC }\end{array}$ & Gene Size, kb & Intron Size, $\%$ \\
\hline CG3777 & 1A1-1A5 & 70.6 & 95.2 \\
\hline CG43867 & $1 \mathrm{C} 5-1 \mathrm{D} 2$ & 119.7 & 94.2 \\
\hline br (broad) & 2B3-2B4 & 70 & 93.5 \\
\hline CG42666 (or prage) & 2B9-2B12 & 79.2 & 96.3 \\
\hline trol (terribly reduced optic lobes) & $3 \mathrm{~A} 3-3 \mathrm{~A} 4$ & 74.9 & 81.9 \\
\hline $\operatorname{sgg}(\operatorname{shaggy})$ & 3A8-3B1 & 43.8 & 93.3 \\
\hline kirre (kin of irre) & $3 B 4-3 C 7$ & 393.7 & 98.4 \\
\hline dnc (dunce) & 3C9-3D1 & 167.3 & 94.8 \\
\hline Nrg (Neuroglian) & 7F2-7F4 & 37.7 & 80.4 \\
\hline dlg1 (discs large 1) & 10B6-10B10 & 40.1 & 81.9 \\
\hline EcR (Ecdysone receptor) & 42A9-42A12 & 78.6 & 93.5 \\
\hline Hr46 (Hormone receptor-like in 46 or Hormone receptor 3 ) & $46 \mathrm{~F} 5-46 \mathrm{~F} 7$ & 31.8 & 86.7 \\
\hline Eip74EF (Ecdysone-induced protein $74 E F)$ & 74D4-74E2 & 59.1 & 89.8 \\
\hline Eip75B (Ecdysone-induced protein $75 B)$ & 75A10-75B6 & 113.7 & 94.8 \\
\hline Eip78C (Ecdysone-induced protein $78 \mathrm{C})$ & $78 \mathrm{C} 2-78 \mathrm{C} 3$ & 39.5 & 86.8 \\
\hline
\end{tabular}

\subsection{Long Genes Mapping In Polytene Chromosomes Bands and Interbands}

\subsubsection{CG3777}

CG3777 is located on chromosome $\mathrm{X}$ in the 1A1-1A5 region (according to UCSC genome browser data http://genome.ucsc.edu/, Table 1). The gene length is $70.6 \mathrm{~kb}(95.2 \%$ of it accrues to introns); three transcripts are read from CG3777 (only the longest and the shortest are shown in Figure 6D, Table 1). Within the introns of CG3777-RB four other genes are located: CG13375, CG12470, Or1a (Odorant receptor 1a), and partly CG32816 (Figure 6A-D, Table S3). According to the 4HMM model, the introns of CG3777 throughout its length mostly contain malachite (42.0\%) with several inclusions of ruby chromatin (34.6\%), which correspond to neutral chromatin state (96.6\%) (Figure 6B,C) [32,39]. Probes for FISH were picked from the 5'- and 3'-ends of CG3777-RB (red and green arrows in Figure 6D,E). The analysis showed that two probes, being separated by $69.5 \mathrm{~kb}$, are detected as two distinct signals in 
the interbands 1A6/A7 and 1B1-2/B3-4 (Figure 6D-H). According to Bridges' map [25], two interbands, two grey, and one black band are situated between the two probes. As not all bands from Bridges' map are distinguishable on chromosome preparations, 1B1-2 is the only band visible in Figure 6G. It is composed of intron material that is $\sim 67 \mathrm{~kb}$ in length (Figure 6).

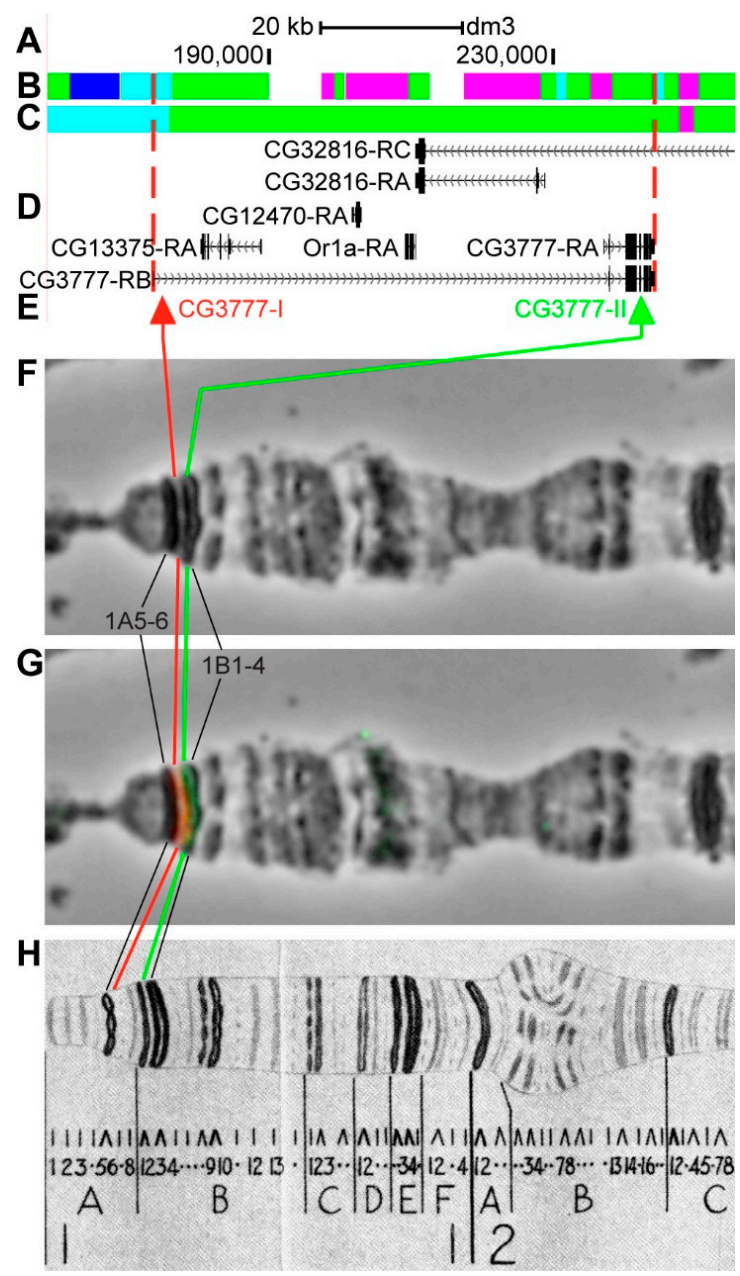

Figure 6. Localization of the CG3777 gene in the $1 \mathrm{AB}$ region (the gene is bound by red dotted lines). (A) the scale (kb) and genomic coordinates (bp); (B) the four chromatin-state model [39]; (C) the chromatin condensation level model [32]; (D) genes location (arrow lines show the gene orientation and black bars indicate the location of gene exons); (E) probes location; (F) phase-contrast micrograph of the region; (G) combined fluorescence in situ hybridization (FISH) signals; and, (H) C. Bridges' chromosome map [25].

\subsubsection{CG43867}

CG43867 is located on chromosome $\mathrm{X}$ in the region from 1C5 to 1D2 (according to UCSC, Table 1). The gene length is $119.7 \mathrm{~kb}$ (94.2\% of it accrues to introns); nine transcripts are read from CG43867 (only longest and the shortest are shown in Figure 7D, Table 1). Within the introns of CG43867-RA, six other genes are located: CG14635, CG3713, CG14634, CG11664, CG11663, and CG3711 (Figure 7A-D, Table S3). According to the $4 \mathrm{HMM}$ model, the introns of CG43867 throughout its length mostly contain malachite $(60.2 \%)$ with small inclusions of ruby chromatin $(6.0 \%)$, which correspond to neutral chromatin state (92.6\%) (Figure 7B,C). CG3711 and two groups of exons on the 3'-end of CG43867 correspond to the body of these genes and form lazurite chromatin (17.2\%), which corresponds to neutral chromatin state (Figure 9A-D) [32,39]. The probes for FISH were picked from the 3'- and 5'-ends of CG43867-RA (red and green arrows in Figure 7D,E). The analysis showed that two probes, separated by $116.0 \mathrm{~kb}$, are 
detected as two distinct signals in the interbands 1C4-5/D1-2 and 1D1-2/D3 proximal and distal of loose grey band 1D1-2 (Figure 7D-H). According to Bridges' map [25], two interbands and one grey band, composed of intron material that is $\sim 112 \mathrm{~kb}$ in length, are situated between the two probes (Figure 7).

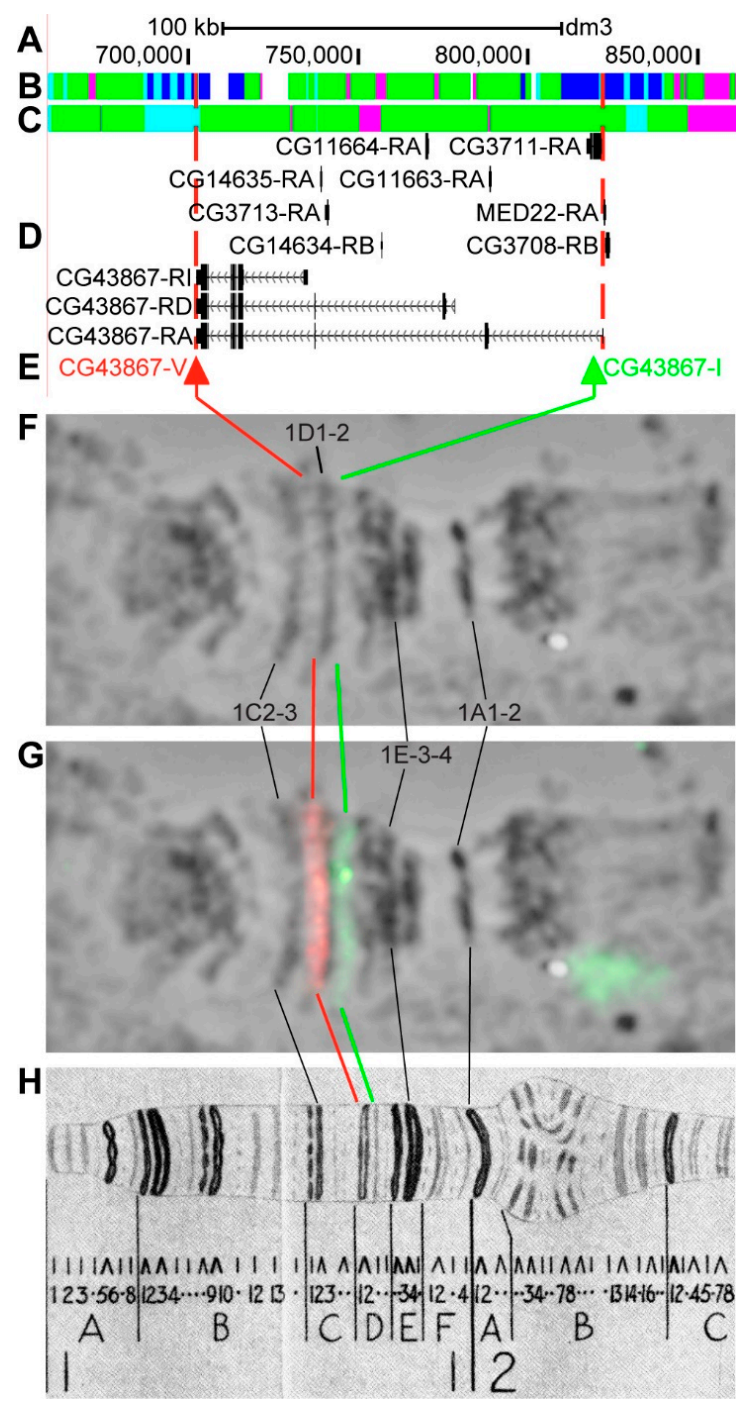

Figure 7. Localization of the CG43867 gene in the 1 CD region (the gene is bound by red dotted lines). (A) the scale (kb) and genomic coordinates (bp); (B) the four chromatin-state model [39]; (C) the chromatin condensation level model [32]; (D) genes location (arrow lines show the gene orientation and black bars indicate the location of gene exons); (E) probes location; (F) phase-contrast micrograph of the region; (G) combined FISH signals; and, (H) C. Bridges' chromosome map [25].

\subsection{3. $b r$}

Previous cytogenetic and EM data show that $b r$ (broad) is located on the chromosome $\mathrm{X}$ in the 2B5 band (in the 2B3-2B4 region according to UCSC, Table 1) and two proximally neighboring genes dor (deep orange) and $h f w$ (halfway) in 2B6 band [50-53]. The gene length is $70.0 \mathrm{~kb}$ (93.5\% of it accrues to introns); 14 transcripts are read from br (only four are shown in Figure 8D, Table 1). Almost two-thirds of $b r-R N$ is overlaid by Mur2B (Mucin related 2B), which is located in the alternative chain (Figure $8 \mathrm{~A}-\mathrm{D}$, Table S3). Introns of $b r$ throughout its length mostly contain malachite (39.9\%) with several inclusions of ruby chromatin $(20.3 \%)$, which mostly correspond to closed $(46.5 \%)$ and neutral chromatin state $(41.8 \%)$, according to the 4HMM model (Figure 8B,C). Two groups of exons on the 3 '-end of the gene correspond to the body of $b r$ and form lazurite chromatin (15.7\%), which corresponds to neutral chromatin state 
(Figure 8A-D) [32,39]. br encodes the key protein that is necessary for the ecdysone cascade of genes and it has several activity cycles. It is induced at a high ecdysone titer (so the 2B puff appears), and then the gene is inactivated at a low ecdysone titer and such a cycle is repeated twice at the end of larval development $[50,54]$. This chromosome region is morphologically complex, because the bands form contacts with each other and a special puff-like structure appears (Figure 8) [4,51]. Therefore, for the preparations, we used chromosomes on the $0 \mathrm{~h}$ prepupa stage when the puff is already inactive. Probes for FISH were picked from the $5^{\prime}$-end of $b r-R N$ and $3^{\prime}$-end of dor-RA (red and green arrows in Figure $8 \mathrm{D}, \mathrm{E})$. The analysis showed that, when the puff is not in its active stage, two probes, separated by $88.7 \mathrm{~kb}$, are detected as two distinct signals: br-I is localized in the proximal part of 2B3-4, and dor is proximally situated from it (Figure $8 \mathrm{D}-\mathrm{H}$ ). The complicated chromosome structure in this region does not allow for distinct identification of the $2 \mathrm{~B} 5$ band, in which the intron part of $b r$ is located (Figure 8).

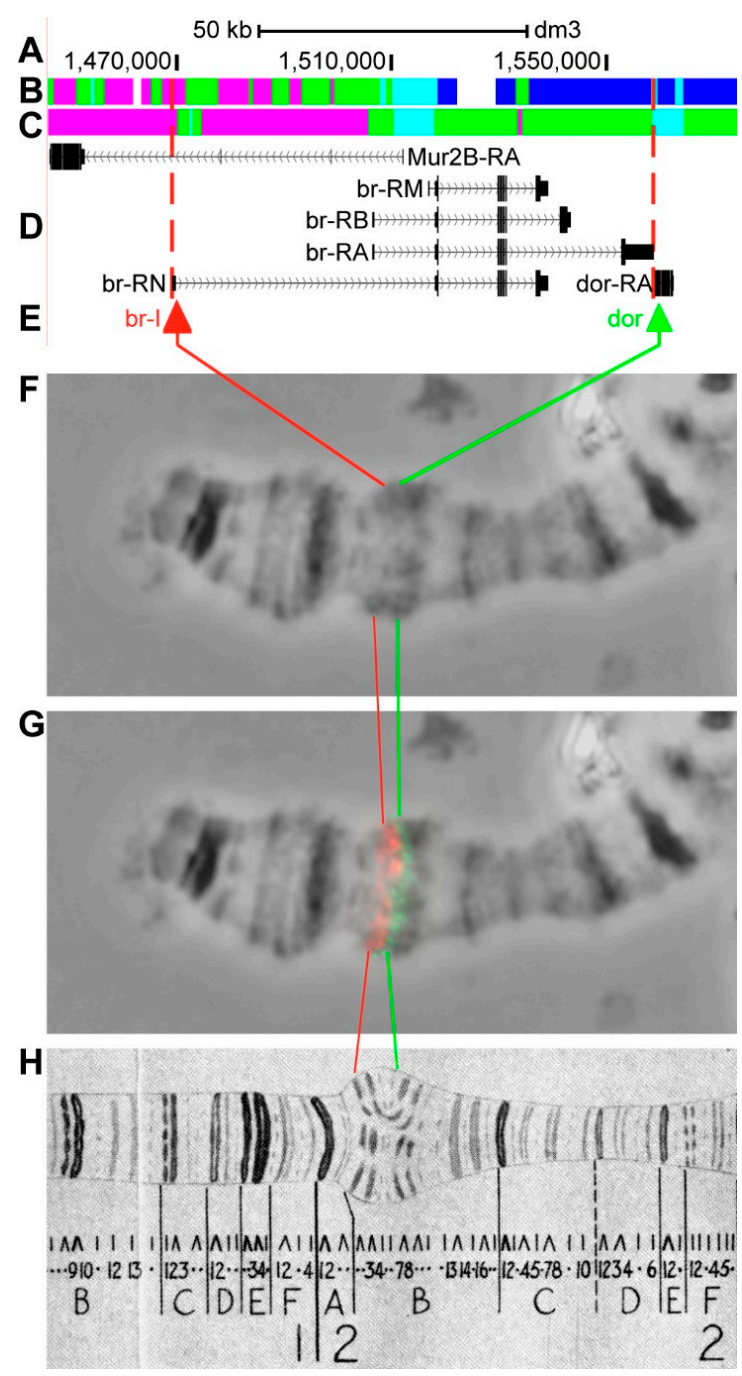

Figure 8. Localization of the $b r$ gene in the $2 \mathrm{~B}$ region (the gene is bound by red dotted lines). (A) the scale (kb) and genomic coordinates (bp); (B) the four chromatin-state model [39]; (C) the chromatin condensation level model [32]; (D) genes location (arrow lines show the gene orientation and black bars indicate the location of gene exons); (E) probes location; (F) phase-contrast micrograph of the region; (G) combined FISH signals; and, (H) C. Bridges' chromosome map [25].

\subsection{4. $C G 42666$}

CG42666 (prage) is located on chromosome $\mathrm{X}$ in the 2B9-B12 region (according to UCSC, Table 1). The gene length is $79.2 \mathrm{~kb}$ (96.3\% of it accrues to introns); 11 transcripts are read from CG42666 
(only three are shown in Figure 9D, Table 1). Within the introns of CG42666-RG four other genes are located: Adar (Adenosine deaminase acting on RNA), CG32806, CG14810, and CG14811 (Figure 9A-D, Table S3). According to the $4 \mathrm{HMM}$ model, the introns of CG42666 throughout its length mostly contains malachite (31.8\%) with several inclusions of aquamarine (23.0\%) and ruby chromatin (3.0\%), which mostly correspond to open $(37.6 \%)$ and neutral chromatin state (50.4\%) (Figure 9B,C). Two groups of exons on the 3'-ends of CG42666 and Adar correspond to the bodies of these genes and form lazurite chromatin $(40.6 \%)$, which corresponds to open and neutral chromatin state (Figure 9A-D) [32,39]. Probes for FISH were picked from the 5'- and 3'-ends of CG42666-RG (red and green arrows in Figure 9D,E). The analysis showed that two probes, separated by $76.5 \mathrm{~kb}$, are detected as two distinct signals in the interbands 2B7-8/B9-10 and 2B9-10/B11 proximal and distal of loose grey band 2B9-10 (Figure 9D-H). According to Bridges' map [25], two interbands and one grey band, being composed of intron material that is $\sim 76 \mathrm{~kb}$ in length, are situated between the two probes (Figure 9).

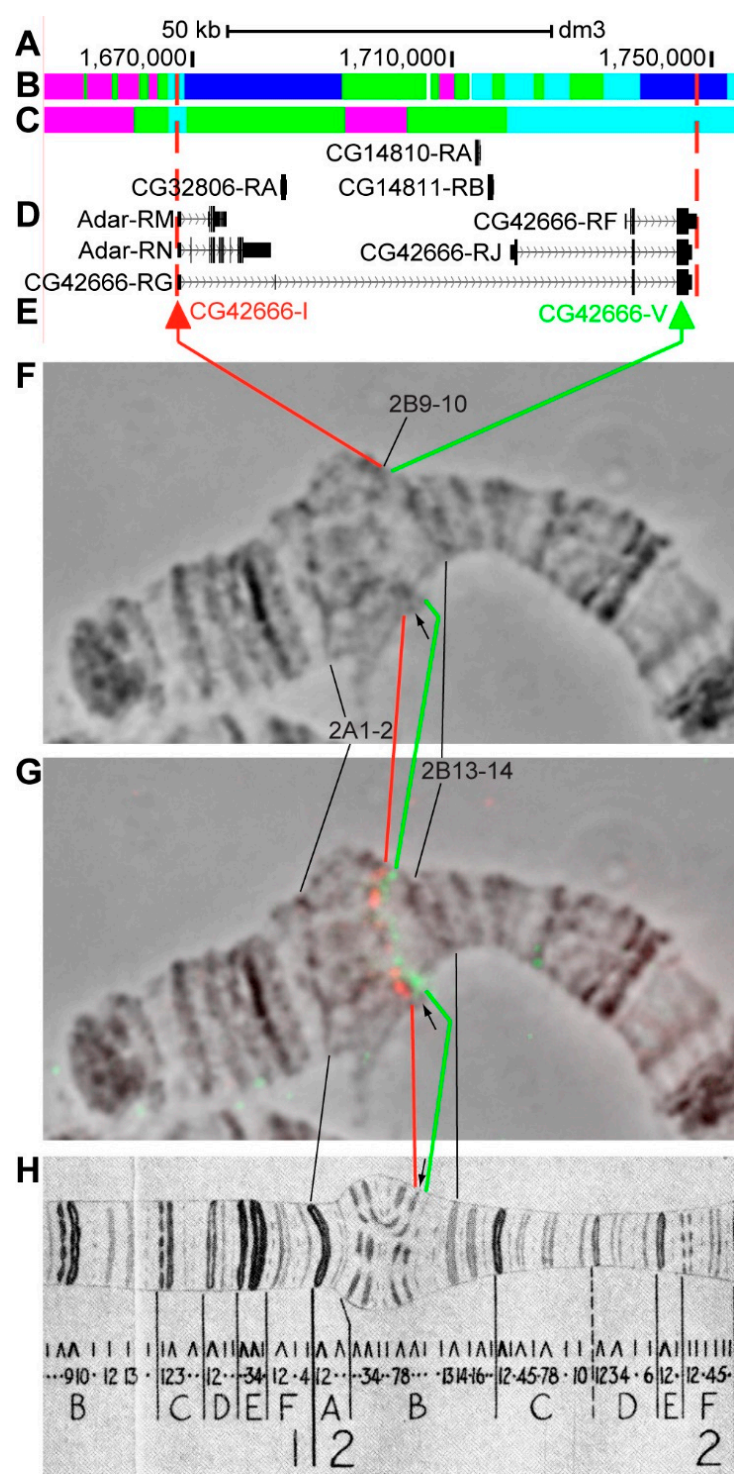

Figure 9. Localization of the CG42666 gene in the $2 \mathrm{~B}$ region (the gene is bound by red dotted lines). (A) the scale (kb) and genomic coordinates (bp); (B) the four chromatin-state model [39]; (C) the chromatin condensation level model [32]; (D) genes location (arrow lines show the gene orientation and black bars indicate the location of gene exons); (E) probes location; (F) phase-contrast micrograph of the region; (G) combined FISH signals; and, (H) C. Bridges' chromosome map [25]. 


\subsection{5. trol}

trol (terribly reduced optic lobes) is located on chromosome $\mathrm{X}$ in the 3A3-3A4 region (according to UCSC, Table 1). The gene length is $74.9 \mathrm{~kb}(81.9 \%$ of it accrues to introns); 18 transcripts are read from trol (only three are shown in Figure 10D, Table 1). Introns of trol throughout its length mostly contain malachite (52.0\%) with two inclusions of aquamarine chromatin (5.2\%), which mostly correspond to closed $(70.7 \%)$ and neutral chromatin state $(29.3 \%)$, according to the 4 HMM model (Figure 10B,C). Four groups of exons on the 3 '-end and in the middle of trol correspond to the body of this gene and form lazurite chromatin (42.7\%), which corresponds to closed and neutral chromatin state (Figure 10A-D) [32,39]. Probes for FISH were picked from the 3'- and 5'-ends of trol-RZ (green and red arrows in Figure 10D,E). The analysis showed that two probes, being separated by $71.8 \mathrm{~kb}$, are detected as two distinct signals in the black band 3A1-2 and in the interband 3A3/A4 (Figure 10D-H). According to Bridges' map [25], one dense band, two interbands, and partly the adjacent black band are situated between the two probes (Figure 10).

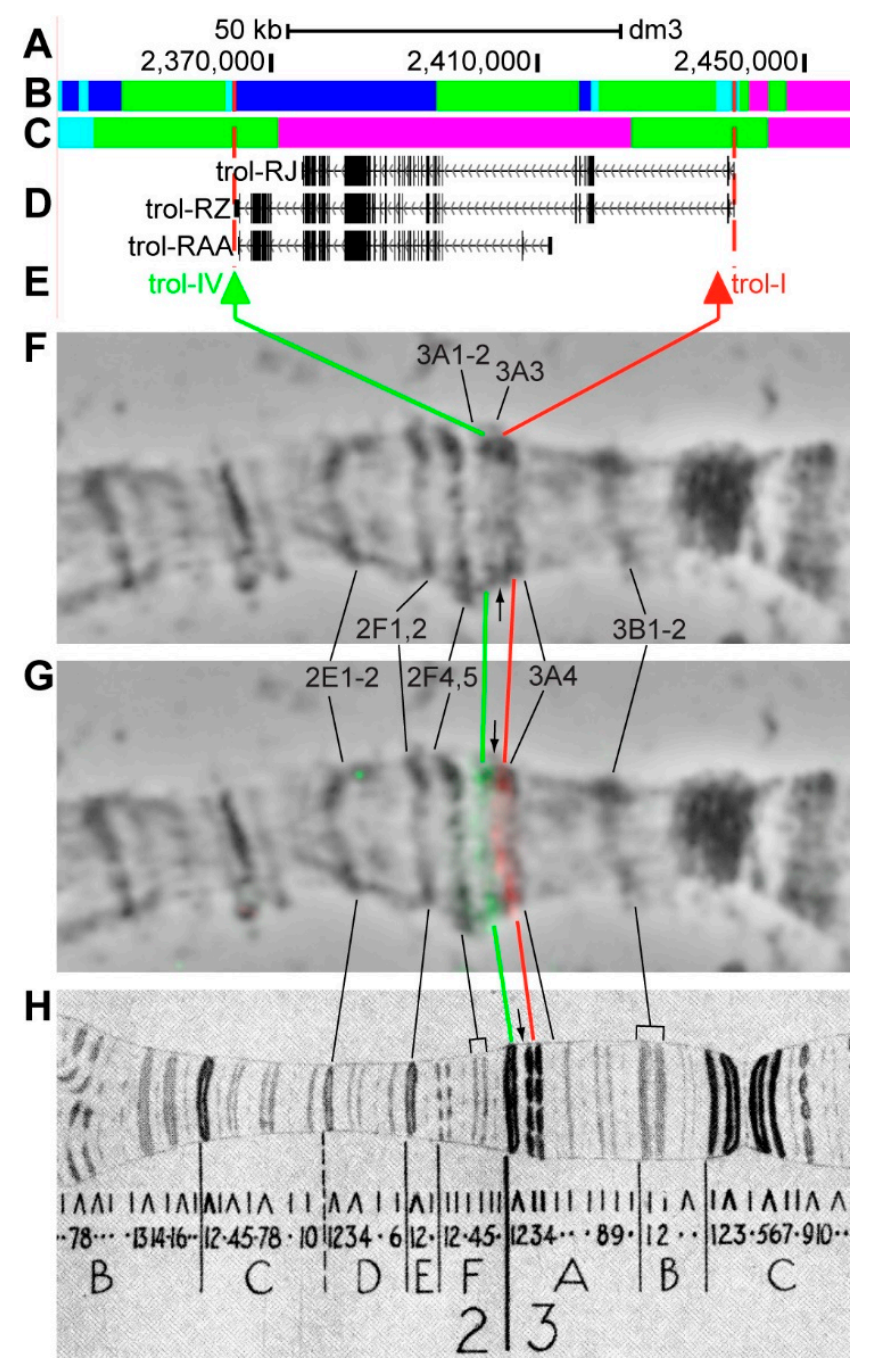

Figure 10. Localization of the trol gene in the 3A1-4 region (the gene is bound by red dotted lines). (A) the scale $(\mathrm{kb})$ and genomic coordinates (bp); (B) the four chromatin-state model [39]; (C) the chromatin condensation level model [32]; (D) genes location (arrow lines show the gene orientation and black bars indicate the location of gene exons); (E) probes location; (F) phase-contrast micrograph of the region; (G) combined FISH signals; and, (H) C. Bridges' chromosome map [25]. 


\subsection{6. $s g g$}

sgg (shaggy) is located on chromosome $\mathrm{X}$ in the 3A8-3B1 region (according to UCSC, Table 1). The gene length is $43.8 \mathrm{~kb}$ (93.3\% of it accrues to introns); 17 transcripts are read from sgg (only three are shown in Figure 11D, Table 1). Introns of $s g g$ throughout its length mostly contain aquamarine (56.9\%) and malachite chromatin (19.7\%), which correspond to open $(68.5 \%)$ and neutral chromatin state $(31.4 \%)$, according to the $4 \mathrm{HMM}$ model (Figure 11B,C). Five groups of exons on the $3^{\prime}$-end of the gene correspond to the body of $s g g$ and form lazurite chromatin $(21.4 \%)$, which corresponds to active chromatin state (Figure 11A-D) [32,39]. The probes for FISH were picked from the most close to the $5^{\prime}$ - and $3^{\prime}$-end areas of $s g g-R A$ (red and green arrows in Figure 11D,E). The analysis showed that two probes, separated by $42.4 \mathrm{~kb}$, are detected as two distinct signals in the interbands 3A7/A8 and 3A10/B1 (Figure 11D-H). According to Bridges' map [25], the whole 3A region is represented by several thin loose bands, which are very hard to distinguish with light microscopy methods. The 3A8-3A10 region comprises three neighboring bands that are composed of condensed material, which looks like a loose band that is situated between the two probes (Figure 11).

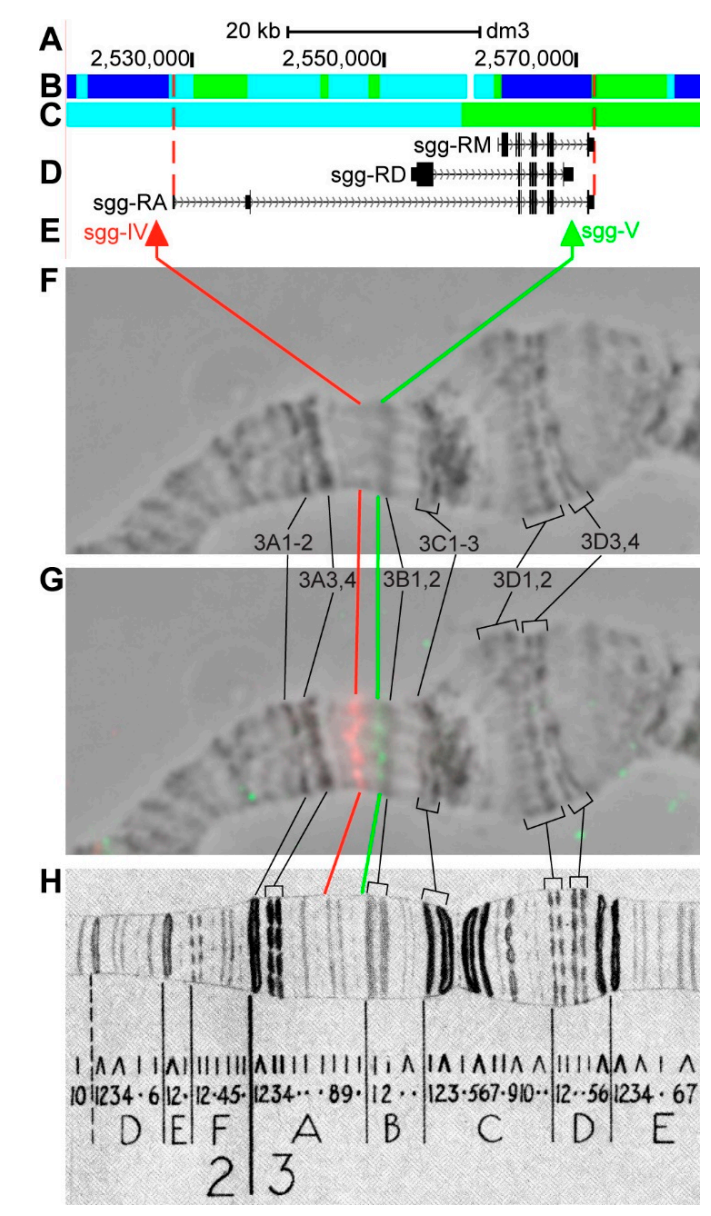

Figure 11. Localization of the $\mathrm{sgg}$ gene in the $3 \mathrm{AB}$ region (the gene is bound by red dotted lines). (A) the scale (kb) and genomic coordinates (bp); (B) the four chromatin-state model [39]; (C) the chromatin condensation level model [32]; (D) genes location (arrow lines show the gene orientation and black bars indicate the location of gene exons); (E) probes location; (F) phase-contrast micrograph of the region; (G) combined FISH signals; and, (H) C. Bridges' chromosome map [25].

\subsection{7. kirre}

kirre (kin of irre) is located between sgg and $d n c$ (dunce) approximately in the 3C1-3C8 region (in the $3 B 4-3 C 7$, according to UCSC, Table 1) and has a unique gene structure, but yet it has not been localized 
on the polytene chromosome map. The gene length is $393.7 \mathrm{~kb}$ (98.4\% of it accrues to introns); seven transcripts are read from kirre (only the longest and the shortest are shown in Figure 12D, Table 1). Twenty-three other genes are located within the introns of kirre-RF (Figure 12A-D, Table S3). According to the $4 \mathrm{HMM}$ model, introns of kirre throughout its length mostly contain ruby (50.5\%) with several inclusions of malachite chromatin $(38.6 \%)$, which mostly correspond to closed chromatin $(82.0 \%)$ with small inclusions of neutral chromatin state (15.5\%) (Figure 12B,C) [32,39]. The probes for FISH were picked from the aquamarine fragments of the gene, which match $5^{\prime}$-end of kirre-RF (kirre-I), $5^{\prime}$-region of CG32795-RD (kirre-II), 3'-end of CG3603-RB (kirre-III), 5'-region of kirre-RD (kirre-IV), and 3'-end of kirre- $R F$ (kirre-V) (red and green arrows in Figure 12D,E). The analysis showed that three probes (kirre-I, kirre-III, and kirre-V) are detected as three distinct signals in the interbands 3B3-4/C1-2, 3C3-4/C5-6, and $3 \mathrm{C} 7 / \mathrm{C} 8$. Two probes (kirre-IV, kirre-V) that are separated by $37.3 \mathrm{~kb}$ are detected as two distinct signals in the central and proximal parts of the 3C5-6 band. Chromosome regions between probes are represented by: thin black band 3C1 (kirre-I/kirre-II), large black band 3C2-3 (kirre-II/kirre-III) and another large black band 3C5-6 (kirre-III/kirre-IV) (Figure 12D-I). Consequently, three black bands and three interbands of the 3C1-6 region are situated within the intron of kirre (Figure 12).

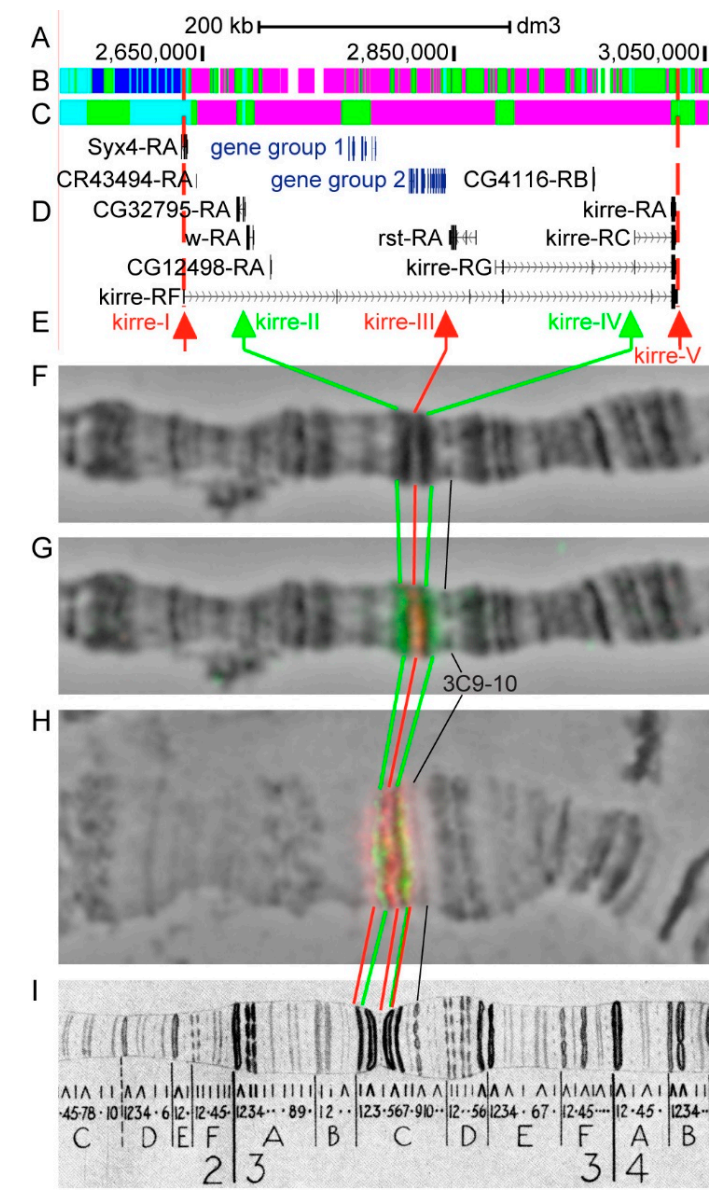

Figure 12. Localization of the kirre gene in the $3 \mathrm{C}$ region (the gene is bound by red dotted lines). (A) the scale (kb) and genomic coordinates (bp); (B) the four chromatin-state model [39]; (C) the chromatin condensation level model [32]; (D) genes location (arrow lines show the gene orientation and black bars indicate the location of gene exons); (E) probes location; (F) phase-contrast micrograph of the region; (G) combined FISH signals on the stretched chromosome preparation for kirre-II, kirre-III, and kirre-IV probes; $(\mathbf{H})$ combined FISH signals for kirre-I, kirre-II, kirre-III, kirre-IV, and kirre-V probes; and, (I) C. Bridges' chromosome map [25]. Gene group 1 is represented by: CG14416, CG14417, CG14418, CG14419, CG3526; gene group 2 is represented by: CG3588, CG14424, CG32793, CG3592, CG3598, CG14420, CG14421, CG14422, CG14423, CG17959, CG3603. 


\subsection{8. $d n c$}

$d n c$ (dunce) is located on chromosome $\mathrm{X}$ in the 3C9-3D1 region (according to UCSC, Table 1); Khoroshko et al. [45] more accurately defined its location in the region between interbands $3 \mathrm{C} 7 / \mathrm{C} 8-3 \mathrm{D} 1 / \mathrm{D} 2$. The gene length is $167.3 \mathrm{~kb}(94.8 \%$ of it accrues to introns); 17 transcripts are read from $d n c$ (only four are shown in Figure 13D, Table 1). Eight other genes are located within the introns of $d n c-R T$ (Figure 13A-D, Table S3). According to the $4 \mathrm{HMM}$ model, introns of $d n c$ throughout its length mostly contain ruby (59.5\%) with small inclusions of malachite chromatin (24.2\%), which correspond to closed chromatin $(70.5 \%)$ with small inclusions of neutral chromatin state $(24.8 \%)$ (Figure 13B,C) [32,39]. The probes for FISH were picked from the 5'- and $3^{\prime}$-ends of $d n c-R T$ and from $5^{\prime}$-end of $d n c-R J$, in all the cases matching with fragments of aquamarine chromatin (black arrows in Figure 13D,E). The analysis showed that three probes, which are separated by $78.5 \mathrm{~kb}$ and $85.9 \mathrm{~kb}$, are detected as three distinct signals in the interbands 3C7/C8, 3C9-10/C11-12, and 3D1,2/D3,4 (Figure 13D-I). The distinct location of the dnc-I and dnc-II probes is most visible on the stretched chromosomes preparations (Figure 13F). Seven interbands and six grey bands are situated between the dnc-I and dnc-II probes (Figure 13), according to Bridges' map [25].

\subsection{9. $\mathrm{Nrg}$}

$\mathrm{Nrg}$ (Neuroglian) is located on chromosome $\mathrm{X}$ in the 7F2-7F4 region (according to UCSC, Table 1). The gene length is $37.7 \mathrm{~kb}$ ( $80.4 \%$ accrues to introns); nine transcripts are read from $\mathrm{Nrg}$ (only the longest is shown in Figure 14D, Table 1). One gene is located within the introns of Nrg-RE-PIP82 (Figure 14A-D, Table S3). According to the $4 \mathrm{HMM}$ model, the introns of $\mathrm{Nrg}$ throughout its length mostly contain malachite $(60.3 \%)$ with two small inclusions of ruby chromatin $(7.4 \%)$, which correspond to neutral chromatin state $\left(93.1 \%\right.$ ) (Figure 14B,C). The group of exons on the $3^{\prime}$-end of the gene corresponds to the body of $\mathrm{Nrg}$ and form lazurite chromatin (24.8\%), which corresponds to neutral chromatin state (Figure 14A-D) [32,39]. Probes for FISH were picked from the 5'- and 3'-ends of Nrg-RE (red and green arrows in Figure $14 \mathrm{D}$,E). The analysis showed that two probes, being separated by $36.3 \mathrm{~kb}$, are detected as two distinct signals in the interbands 7F1-2/F3-4 and 7F3-4/F5-6 proximal and distal of the loose grey band 7F3-4 (Figure 14D-H). According to Bridges' map [25], two interbands and one grey band, being composed of intron material that is $\sim 36 \mathrm{~kb}$ in length, are situated between the two probes (Figure 14). 

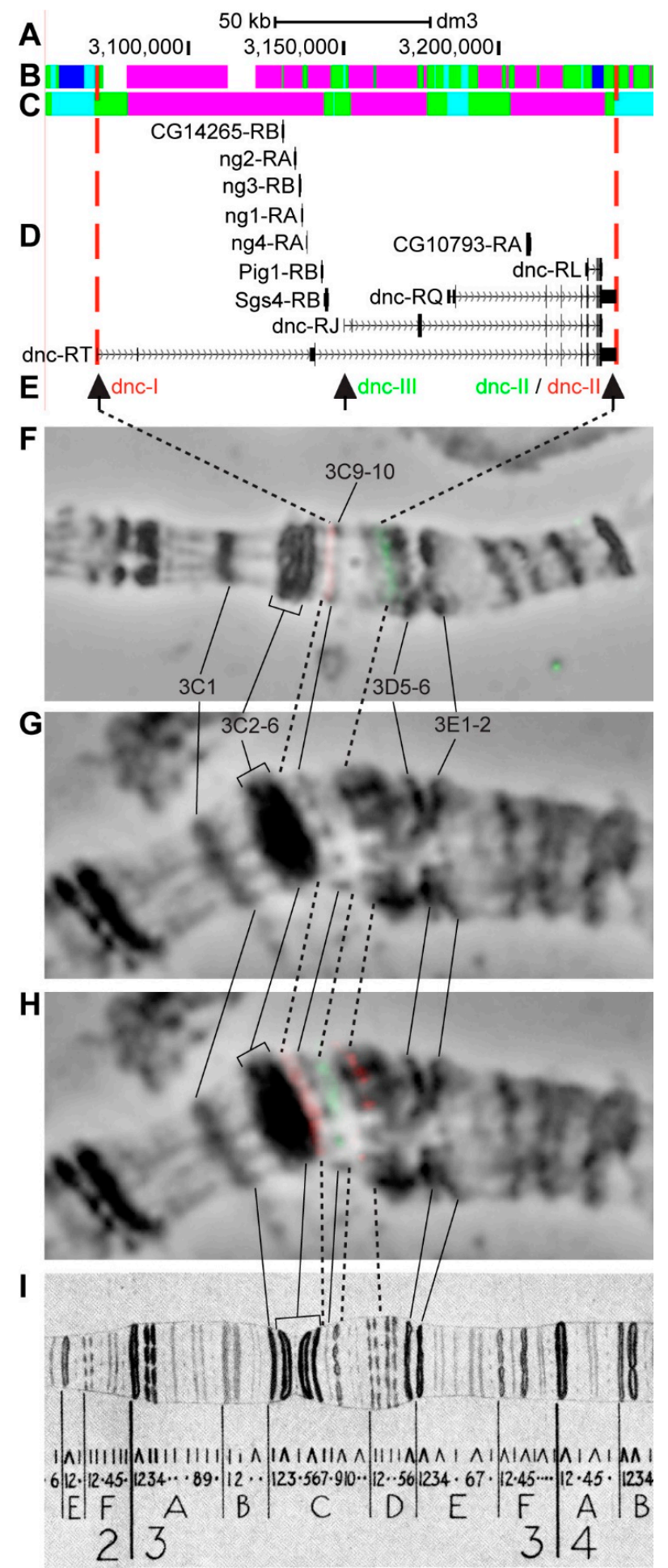

Figure 13. Localization of the $d n c$ gene in the $3 C D$ region (on the molecular map the gene is bound by red dotted lines). (A) the scale (kb) and genomic coordinates (bp); (B) the four chromatin-state model [39]; (C) the chromatin condensation level model [32]; (D) genes location (arrow lines show the gene orientation and black bars indicate the location of gene exons); (E) probes location; (F) combined FISH signals on the stretched chromosome preparation; $(\mathbf{G})$ phase-contrast micrograph of the region; (H) combined FISH signals; and, (I) C. Bridges' chromosome map [25]. 


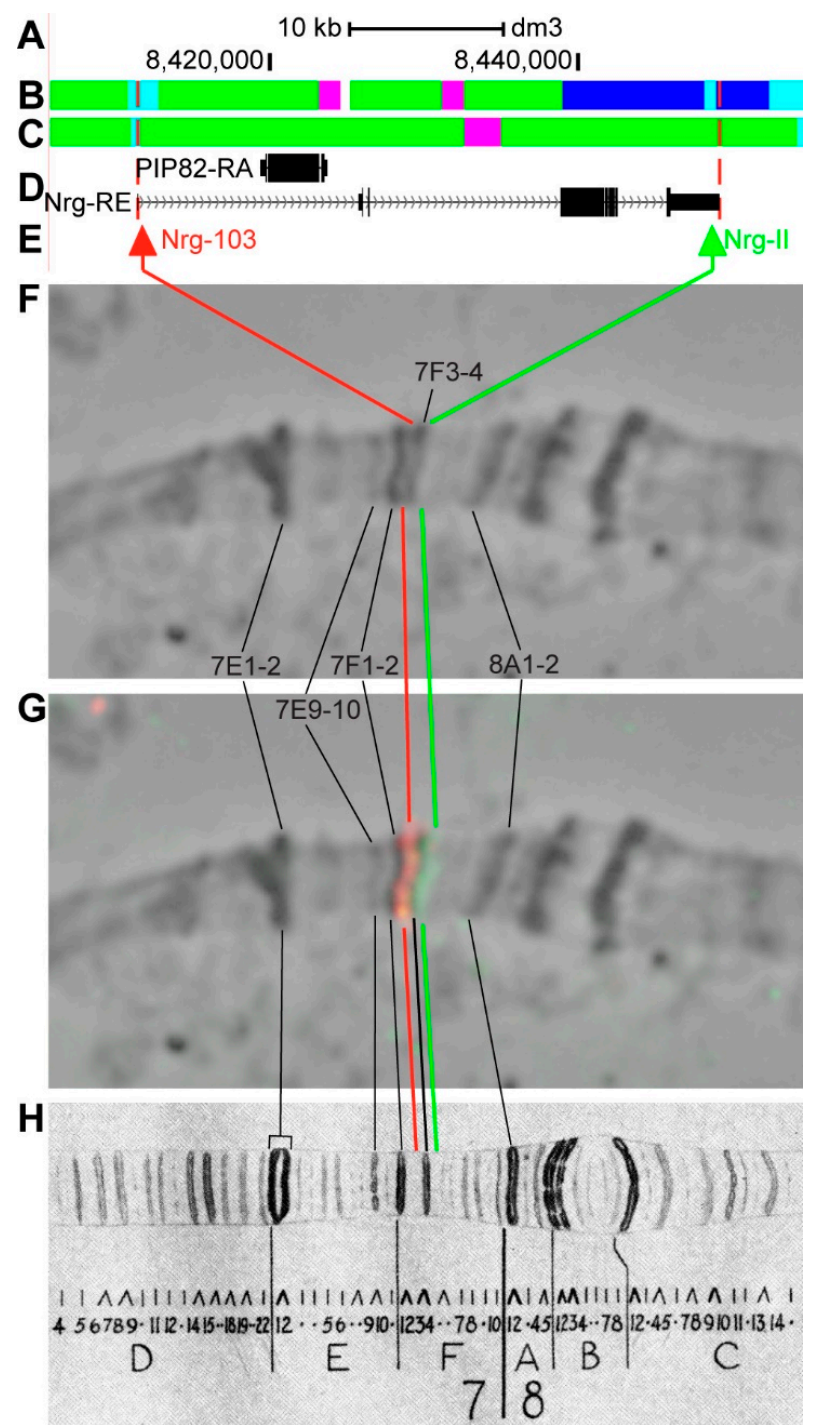

Figure 14. Localization of the $\mathrm{Nrg}$ gene in the 7F region (the gene is bound by red dotted lines). (A) the scale (kb) and genomic coordinates (bp); (B) the four chromatin-state model [39]; (C) the chromatin condensation level model [32]; (D) genes location (arrow lines show the gene orientation and black bars indicate the location of gene exons); (E) probes location; (F) phase-contrast micrograph of the region; (G) combined FISH signals; and, (H) C. Bridges' chromosome map [25].

\subsubsection{0. $d \lg 1$}

dlg1 (discs large 1) is located on chromosome $\mathrm{X}$ in the 10B6-10B11 region (according to UCSC, Table 1); Zhimulev et al. [46] have preliminarily localized it in the 10B8-1011 region. The gene length is $40.1 \mathrm{~kb}(81.9 \%$ of it accrues to introns); 21 transcripts are read from $d l g 1$ (only three are shown in Figure 15D, Table 1). Half of $d l g 1$ introns contain malachite (41.3\%) with one inclusion of ruby chromatin $(3.4 \%)$, which mostly correspond to neutral chromatin state $(48.3 \%)$, according to the $4 \mathrm{HMM}$ model (Figure 15B,C). Four groups of exons on the 3 '-end of the gene correspond to the body of $d l g 1$ and form lazurite chromatin (39.4\%), which corresponds to active chromatin state (51.6\%) (Figure 15A-D) [32,39]. The probes for FISH were picked from Tim 8 and Or10a (Odorant receptor 10a) genes, and from $5^{\prime}$-end of dlg1-RT (red and green arrows in Figure 15D,E). The analysis showed that three probes, which are separated by $20.5 \mathrm{~kb}$ and $26.1 \mathrm{~kb}$, are detected as three distinct signals in the interbands 10B7/B8-9, 10B8-9/10-11, and 10B10-11/B12 (Figure 15D-H). Three interbands and two grey bands are situated between the Tim8 and Or10a probes, according to Bridges' map [25] (Figure 15). 


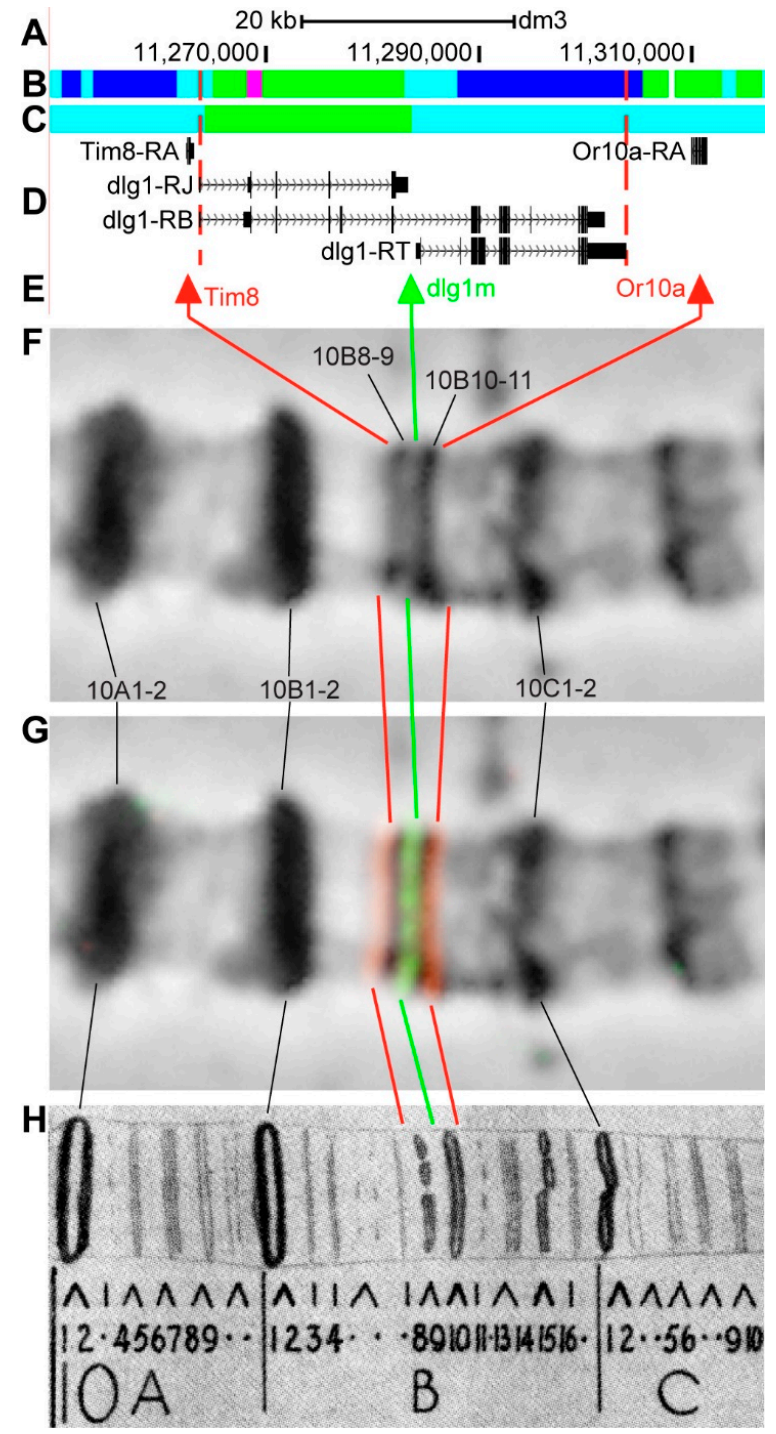

Figure 15. Localization of the $d \lg 1$ gene in the $10 \mathrm{~B}$ region (the gene is bound by red dotted lines). (A) the scale (kb) and genomic coordinates (bp); (B) the four chromatin-state model [39]; (C) the chromatin condensation level model [32]; (D) genes location (arrow lines show the gene orientation and black bars indicate the location of gene exons); (E) probes location; (F) phase-contrast micrograph of the region; (G) combined FISH signals; and, (H) C. Bridges' chromosome map [25].

\subsubsection{EcR}

EcR (Ecdysone receptor) is located on chromosome 2R in the 42A9-42A12 (according to UCSC, Table 1). The gene length is $78.6 \mathrm{~kb}(93.5 \%$ of it accrues to introns); six transcripts are read from $E c R$ (only the longest and the shortest and are shown in Figure 16D, Table 1). Within the introns of $E c R-R A$ two other genes are located: CG14589, CR43904, and also 13 RNA transport genes, which we combined into four groups (Figure $1 \mathrm{~A}-\mathrm{D}$, Table S3). The introns of $E c R$ throughout its length mostly contain malachite (55.2\%), with four inclusions of ruby (7.3\%) and aquamarine chromatin $(24.1 \%)$, which correspond to open $(68.8 \%)$ and neutral chromatin state $(31.1 \%)$, according to the 4HMM model (Figure 16B,C). The group of exons on the 3 '-end of the gene correspond to the body of $E c R$ and form lazurite chromatin (4.8\%), which corresponds to neutral chromatin state (Figure 16A-D) [32,39]. The probes for FISH were picked from the area most close to $3^{\prime}$-end and from $5^{\prime}$-end of $E c R-R A$ (green and red arrows in Figure 16D,E). The analysis showed that two probes, separated by $79.6 \mathrm{~kb}$, are detected as two distinct signals in the 42A12-A16 region (Figure 14D-H). Two probes bound a small 
section of compact material, presumably the $42 \mathrm{~A} 15$ band, which derives from the intron (black arrow in Figure 16F-H). In this grey decondensed band between the two probes, three clusters of transport RNA genes are located (Figure 16D,E).

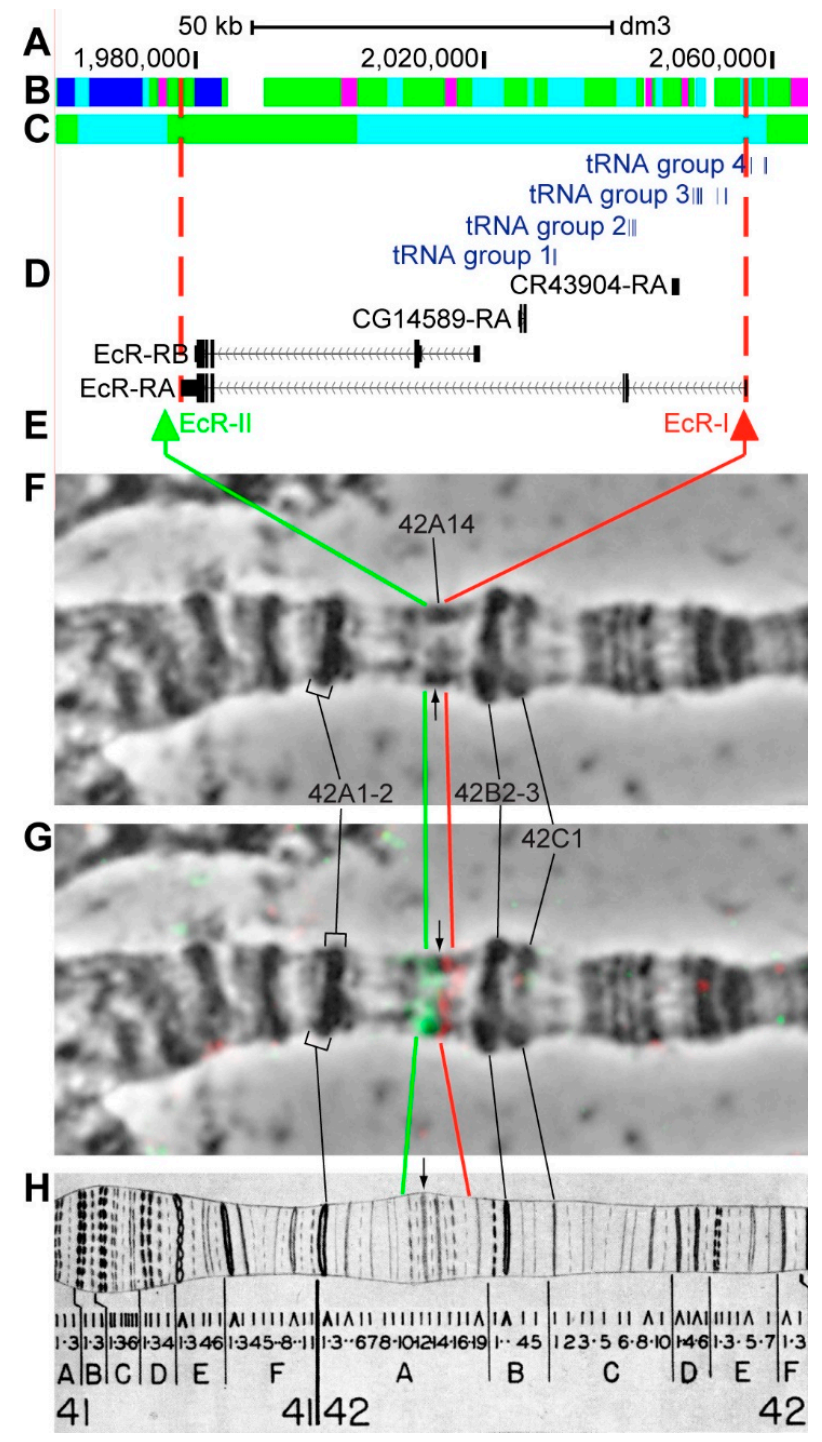

Figure 16. Localization of the $E c R$ gene in the $42 \mathrm{~A}$ region (the gene is bound by red dotted lines). (A) the scale (kb) and genomic coordinates (bp); (B) the four chromatin-state model [39]; (C) the chromatin condensation level model [32]; (D) genes location (arrow lines show the gene orientation and black bars indicate the location of gene exons); (E) probes location; (F) phase-contrast micrograph of the region; (G) combined FISH signals; and, (H) C. Bridges and P. Bridges' chromosome map [55]. tRNA group 1 is represented by: $t R N A: R 2: 42 A d, t R N A: K 2: 42 A e$; tRNA group 2 is represented by: tRNA:N5:42Ah, tRNA:N5:42Ag, tRNA:N5:42Af; tRNA group 3 is represented by: $t R N A: R 2: 42 A c$, tRNA:N5:42Ac, tRNA:N5:42Ab, tRNA:N5:42Aa, tRNA:K2:42Ac, tRNA:K2:42Ab, tRNA:K2:42Aa; tRNA group 4 is represented by: $t R N A: C R 30316, t R N A: I: 42 A, t R N A: R 2: 42 A b, t R N A: K 2: 42 A d$.

\subsubsection{2. $\mathrm{Hr} 46$}

Hr46 (Hormone receptor-like in 46, Hormone receptor 3) is located on chromosome $2 \mathrm{R}$ in the 46F5-46F7 region (according to UCSC, Table 1). The gene length is $31.8 \mathrm{~kb}$ (86.7\% of it accrues to introns); seven transcripts are read from $\mathrm{Hr} 46$ (only three are shown in Figure 17D, Table 1). One gene is located within the introns of Hr46-RD-CG12912 (Figure 17A-D, Table S3). Introns of Hr46 throughout its length mostly contain ruby (51.0\%), with several inclusions of malachite chromatin (39.5\%), which mostly 
correspond to closed chromatin (66.4\%) with inclusions of neutral chromatin state (31.4\%), according to the $4 \mathrm{HMM}$ model (Figure 17B,C) [32,39]. The probes for FISH were picked from the 3'- and 5'-ends of Hr46-RD (green and red arrows in Figure 17D,E). The analysis showed that two probes, separated by $30.6 \mathrm{~kb}$, are detected as two distinct signals in the black band 46F5-6 and in the interband 46F7/F8 (Figure 17D-H). Hr46, a short and densely packed gene, which is inactive in most tissues, does not allow for clearly seeing the inactive intron material between the probes (Figure 17).

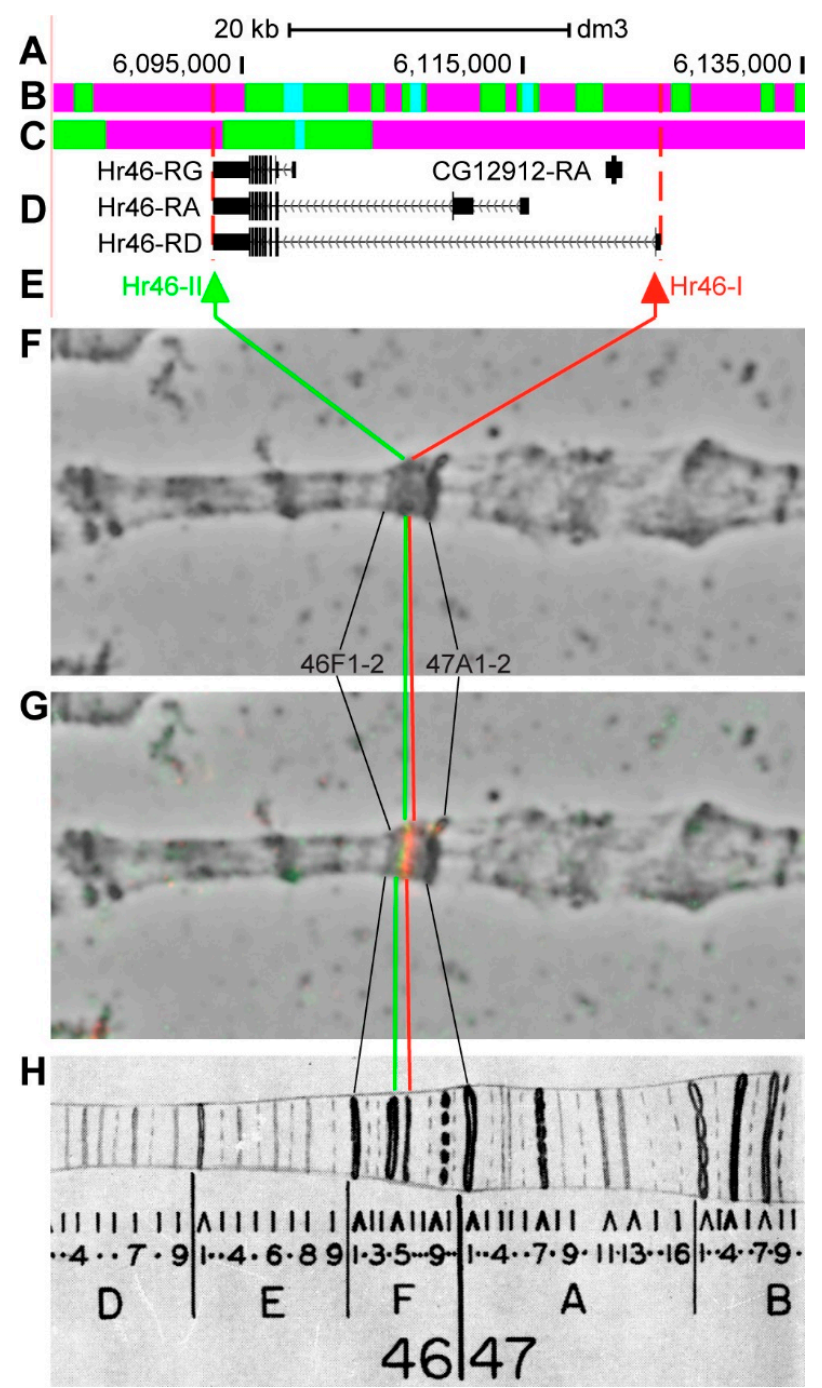

Figure 17. Localization of the Hr46 gene in the $46 \mathrm{~F}$ region (the gene is bound by red dotted lines). (A) the scale $(\mathrm{kb})$ and genomic coordinates (bp); (B) the four chromatin-state model [39]; (C) the chromatin condensation level model [32]; (D) genes location (arrow lines show the gene orientation and black bars indicate the location of gene exons); (E) probes location; (F) phase-contrast micrograph of the region; (G) combined FISH signals; and, (H) C. Bridges' chromosome map [25].

\subsubsection{Eip74EF}

Eip74EF (Ecdysone-induced protein $74 E F$ ) is located on chromosome $3 \mathrm{~L}$ in the region of ecdysone-induced puff, which, according to EM data, is formed by two grey loose bands 74E1 and 74E2 [56]. The gene length is $59.1 \mathrm{~kb}$ (89.8\% of it accrues to introns); five transcripts are read from Eip74-EF (only the longest and the shortest are shown in Figure 18D, Table 1). Introns of Eip74EF throughout its length mostly contain malachite $(60.7 \%)$ with three inclusions of ruby $(7.7 \%)$ and aquamarine chromatin $(27.4 \%)$, which correspond to open $(83.2 \%)$ and neutral chromatin state $(14.3 \%)$, according to the $4 \mathrm{HMM}$ model (Figure 18B,C). The group of exons on the 3 '-end of the gene correspond 
to the body of Eip74EF and form lazurite chromatin (4.0\%), which corresponds to active chromatin state (Figure 18A-D) [32,39]. The probes for FISH were picked from the 3'-end of Eip74EF-RD and $5^{\prime}$-end of Eip74EF-RA (green and red arrows in Figure 18E). The analysis showed that two probes, which are separated by $60.2 \mathrm{~kb}$, are detected as two distinct signals in the interbands 74D5/E1-2 and 74E5/F1 (Figure 18D-I). The distinct location of the probes is most visible on the stretched chromosomes preparations (Figure 18H). According to Bridges' map [57], five interbands and four grey bands are situated between the probes (Figure 18).

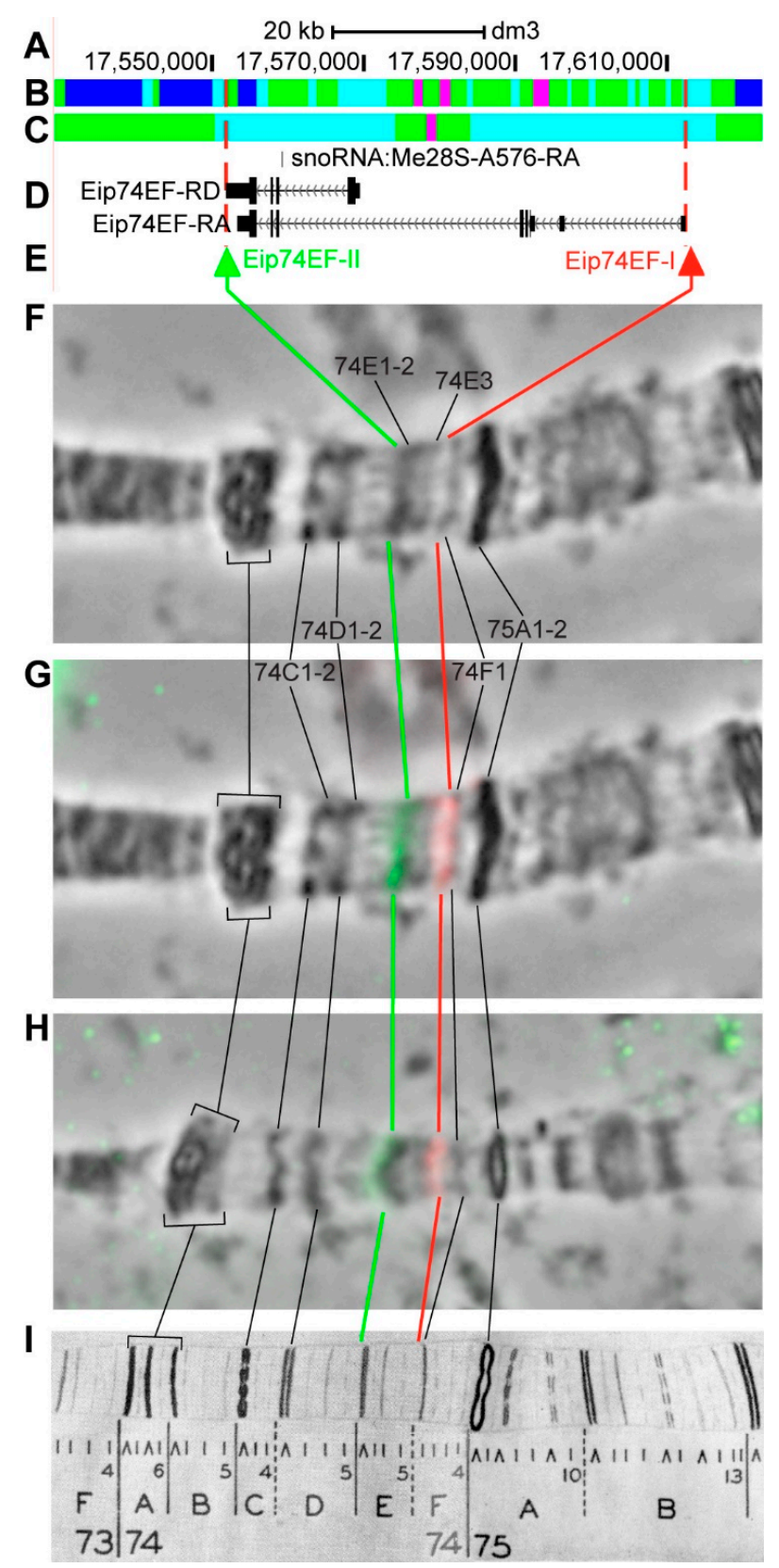

Figure 18. Localization of the Eip74EF gene in the 74E region (the gene is bound by red dotted lines). (A) the scale (kb) and genomic coordinates (bp); (B) the four chromatin-state model [39]; (C) the chromatin condensation level model [32]; (D) genes location (arrow lines show the gene orientation and black bars indicate the location of gene exons); (E) probes location; (F) phase-contrast micrograph of the region; (G) combined FISH signals; $(\mathbf{H})$ combined FISH signals on the stretched chromosome preparation; and, (I) P. Bridges' chromosome map [57]. 


\subsubsection{4. $\operatorname{Eip} 75 B$}

Eip $75 B$ (Ecdysone-induced protein $75 B$ ) is located on chromosome $3 \mathrm{~L}$ in the region of ecdysone-induced puff, which, according to EM data, is formed by five simultaneously decondensed bands 75B1-2, 75B3, 75B4, 75B5, and 75B6-7 of Bridges map [56]. The gene length is $113.7 \mathrm{~kb}(94.8 \%$ of it accrues to introns); six transcripts are read from Eip75B (only four are shown in Figure 19D, Table 1). Within the introns of Eip75B-RF, two other genes are located: CG32192, CG42393, and snoRNA:Me28S-A30 (Figure 19A-D, Table S3). According to the 4HMM model, introns of Eip75B throughout its length mostly contain malachite (46.9\%) with several inclusions of ruby $(11.9 \%)$ and aquamarine chromatin (30.9\%), which correspond to open (48.9\%) and neutral chromatin state $(49.2 \%)$ (Figure 19B,C). The group of exons on the 3'-end of the gene correspond to the body of Eip75B and form lazurite chromatin (2.4\%), which corresponds to active chromatin state (Figure 19A-D) [32,39]. The probes for FISH were picked from the 3'- and 5'-ends of Eip75B-RF (green and red arrows in Figure 19D,E). The analysis showed that two probes, which are separated by $113.2 \mathrm{~kb}$, are detected as two distinct signals on the edge of black band 75B1-2 and in the loose band 75B6-7 (Figure 19D-H). Four interbands and five bands are situated between the probes, according to Bridges' map [57] (Figure 19).

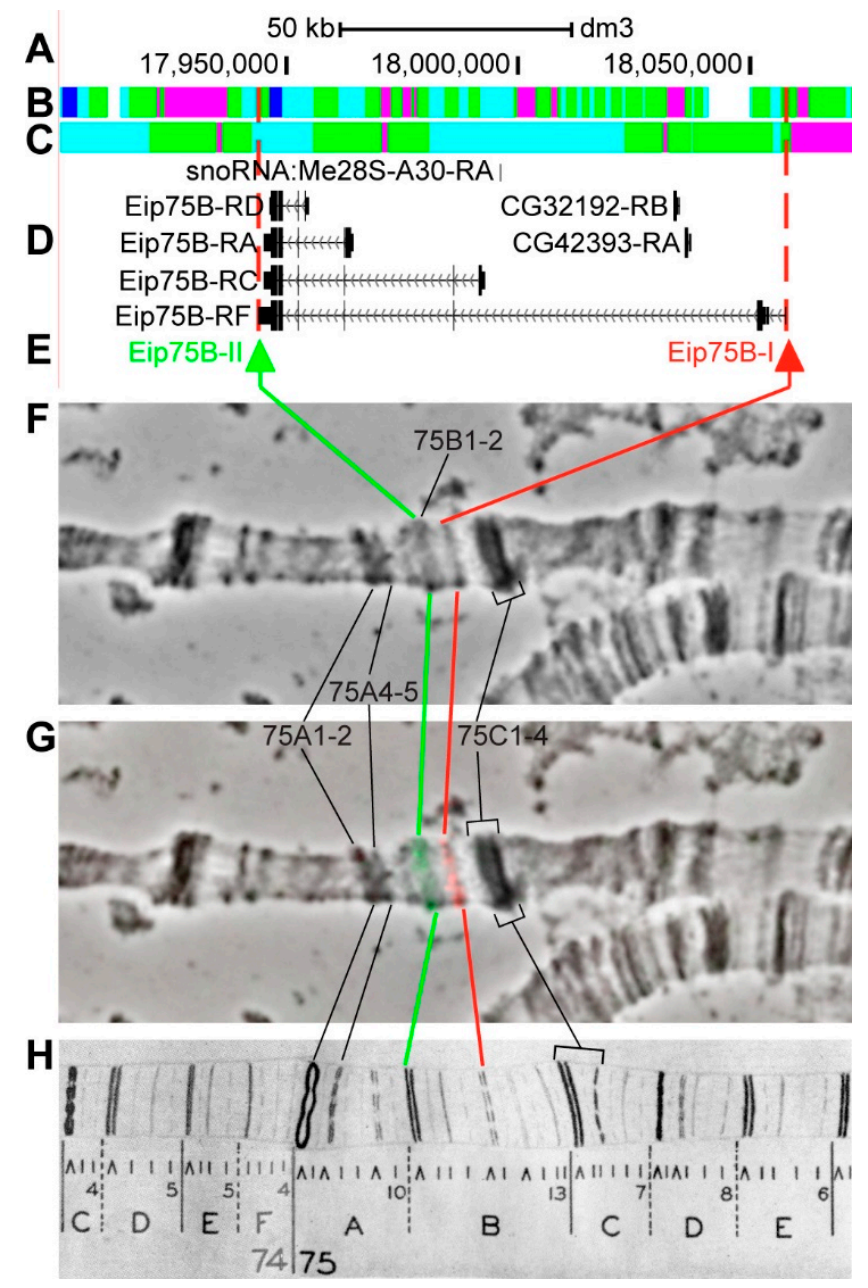

Figure 19. Localization of the Eip75B gene in the 75B region (the gene is bound by red dotted lines). (A) the scale (kb) and genomic coordinates (bp); (B) the four chromatin-state model [39]; (C) the chromatin condensation level model [32]; (D) genes location (arrow lines show the gene orientation and black bars indicate the location of gene exons); (E) probes location; (F) phase-contrast micrograph of the region; (G) combined FISH signals; and, (H) P. Bridges' chromosome map [57]. 


\subsubsection{Eip $78 \mathrm{C}$}

Eip78C (Ecdysone-induced protein 78C) is located on chromosome 3L in the region of ecdysone-induced puff, which, according to EM data, is formed by three grey loose bands 78C4, $78 \mathrm{C} 5-6$ and 78C6, not always being visible under the light microscope [56]. The gene length is $39.5 \mathrm{~kb}$ (86.8\% of it accrues to introns); four transcripts are read from Eip $78 \mathrm{C}$ (only the longest and the shortest are shown in Figure 20D, Table 1). One gene is located within the introns of Eip78C-RA-CG43218 (Figure 20A-D, Table S3). Introns of Eip78C throughout its length mostly contain malachite (39.4\%) with several inclusions of ruby chromatin (25.2\%), which correspond to closed (59.4\%) and neutral chromatin state (28.5\%), according to the $4 \mathrm{HMM}$ model (Figure 20B,C) [32,39]. Probes for FISH were picked from the area most close to 5'-end and from 3'-end of Eip78C-RA (red and green arrows in Figure 20D,E). The analysis showed that two probes, separated by $38.5 \mathrm{~kb}$, are detected as two distinct signals in the interbands 78C3/C4 and 78C5-6/C7 (Figure 20D-H). Three interbands and two bands are situated between the probes, according to Bridges' map [57] (Figure 20).

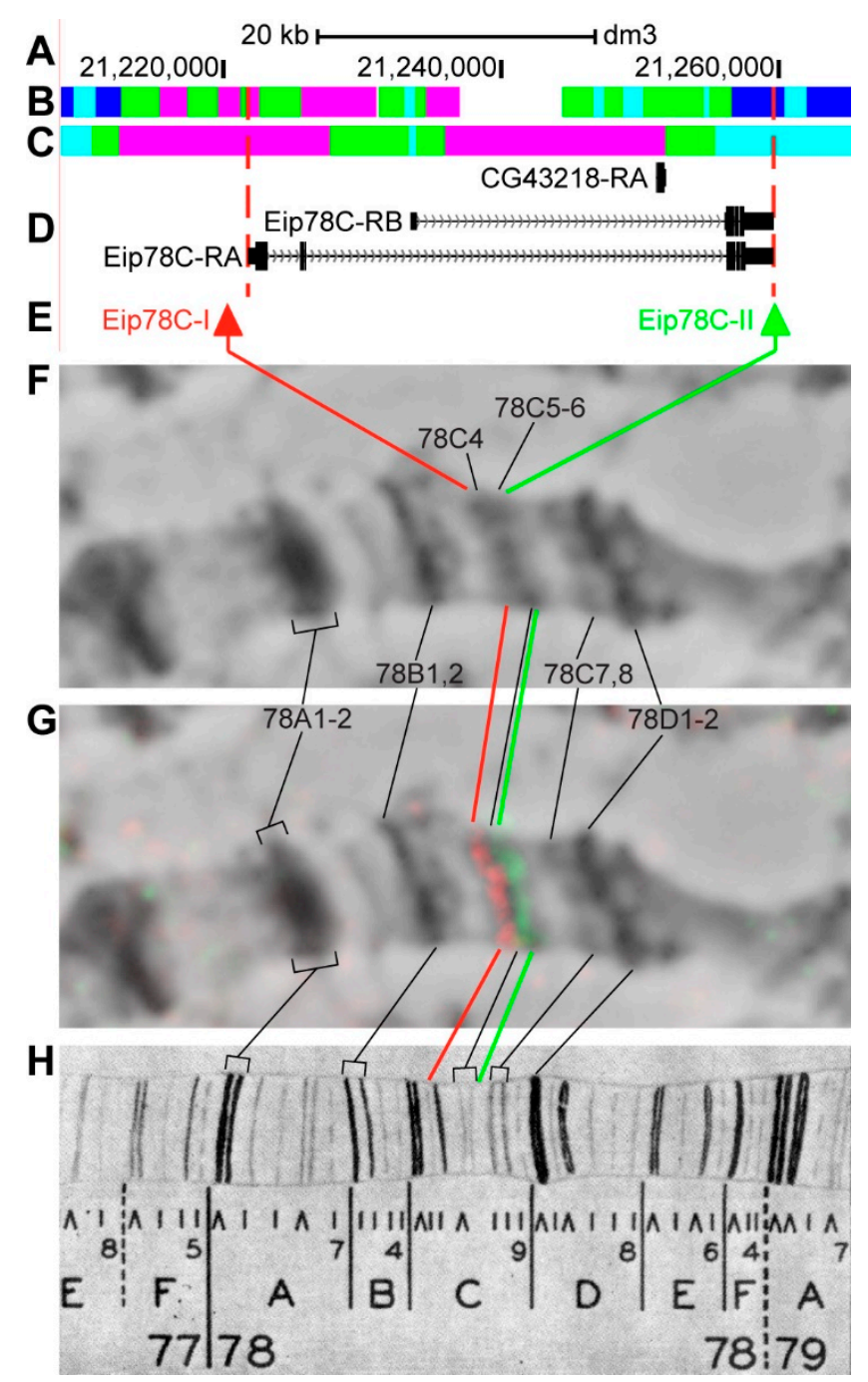

Figure 20. Localization of the Eip78C gene in the 78C region (the gene is bound by red dotted lines). (A) the scale (kb) and genomic coordinates (bp); (B) the four chromatin-state model [39]; (C) the chromatin condensation level model [32]; (D) genes location (arrow lines show the gene orientation and black bars indicate the location of gene exons); (E) probes location; (F) phase-contrast micrograph of the region; (G) combined FISH signals; and, (H) C. Bridges' chromosome map [25]. 


\section{Discussion}

The present study on the distribution of introns in Drosophila genes showed that they are mainly detected in the bodies of housekeeping genes and their length mostly does not exceed $2 \mathrm{~kb}$. The introns are predominantly distributed in lazurite chromatin, which corresponds to gene bodies, and also in adjacent aquamarine and ruby (Figure 2A). In gene bodies, the largest total intron lengths are localized in ruby chromatin along with developmental genes. In almost all long genes with the total intron length over $95 \%$, a significant part of introns is covered with malachite chromatin. Apparently, the gene length increases with increasing intron length, but, at the same time, the proportion of very long genes drops sharply in genes with a length over $50 \mathrm{~kb}$, and especially over $100 \mathrm{~kb}$; their number is no more than 70 (approximately $0.5 \%$ of the total number of genes in the Drosophila genome).

As expected, the distribution of genes and chromatin states corresponds to patterns that were discovered in another study [39]; both the promoters of 12 longest transcripts and the most of alternative transcripts were located in fragments of open aquamarine chromatin and at the chromosome level in interbands, which indicates that these genes pertain to housekeeping. Coding parts of the genes are located in lazurite. The total length of malachite chromatin (mainly introns) in the majority of selected genes comprises $41.9 \%$ of these genes length; ruby totals $28.3 \%$ (Figure 5C). $5^{\prime}$-ends of $b r, H r 46$ and Eip 78C genes are not located in aquamarine chromatin and, subsequently, not in the interbands; the data on gene functioning in target tissues does not indicate that they are involved in housekeeping (Table S3). Hr46 is a tissue-specific gene, because it only functions in the imago brain and Eip 78C is only active in the larval fat body (Table S3). The $b r$ gene is peculiar, because its alternative promoters are found in aquamarine and apparently in the 2B3-4/B5 interband. It should be noted that this gene is located in the most difficult for cytological mapping $2 \mathrm{~B}$ region $[4,50,51]$ and, therefore, it is difficult to draw conclusions regarding the gene localization. The predominant states of chromatin in these three genes are ruby and malachite, as well as the neutral and closed chromatin condensation states [32] (Figure 8C, Figure 17C, Figure 20C).

Figures 21-23 show how genes that are composed of introns form bands and interbands. In the most common case, bands that formed from intron material are located between the promoter at the $5^{\prime}$-end and the intergenic region (interband) at the $3^{\prime}$-end of the gene (Figure 21). A band of this kind is genetically and molecularly heterogeneous, since it contains the intron material (ruby and malachite) and exons of the gene (lazurite) (Figure 21A). Within the noncoding intron of the predominant long "main" gene, one or several differently directed genes are located; in some cases, there are no such genes (Figure 21B,C). This type includes bands that formed from the introns in CG3777 (1A8-1B1-2), CG43867 (1D1-2), CG42666 (2B9-10), trol (3A1-3), sgg (3A9-10), Nrg (7F2-4), EcR (42A14), Eip74EF (bands in 74EF region), and Eip75B (bands in 75B region).

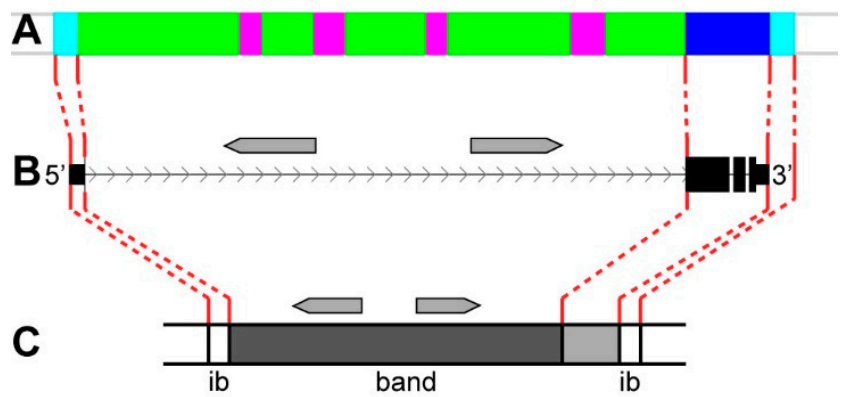

Figure 21. The scheme of the polytene chromosome band organization. The predominant long "main" gene contains exons and intron material; grey arrows represent shorter genes located within the introns of the "main" gene. (A) the four chromatin-state model [39]; (B) studied genes; and, (C) bands and interbands (ib) of polytene chromosome structure comprising the genes studied.

$\mathrm{br}, \mathrm{Hr} 46$, and Eip $78 \mathrm{C}$ are partly similar to the type that is described above; as developmental genes they do not start in aquamarine. However, there is a lot of material in the gene body and it forms a dense 
grey clot, which is not a band, but it easily separates the signals of the gene start and end. Therefore, the material between the gene start and end looks grey, loose, and semi-condensed, and it is not a usual band, as it is genetically heterogeneous and contains both protein-coding and intron material.

In some cases, bands are formed from intron material, as shown in the $d l g 1$ and $d n c$ genes. The promoter of the $d \lg 1$ gene and the alternative promoter (situated in the middle of the DNA fragment occupied by the gene) are both located in aquamarine, on cytological map matching with interbands (Figure 15, Figure 22). A $20 \mathrm{~kb}$ intron covered with malachite and one ruby inclusion is situated between the distal and middle promoters. It forms the 10B8-9 band that only contains intron DNA of the dlg1 gene (Figure 15, Figure 22A,B). The second 10B10-11 band is formed from the material located between the middle promoter and the $3^{\prime}$-end of the gene; it comprises introns and protein-coding parts of the gene (Figure 15, Figure 22B). Thus, $d l g 1$ occupies five chromosome structures of the polytene chromosome $\mathrm{X}$, i.e. two bands and three interbands.

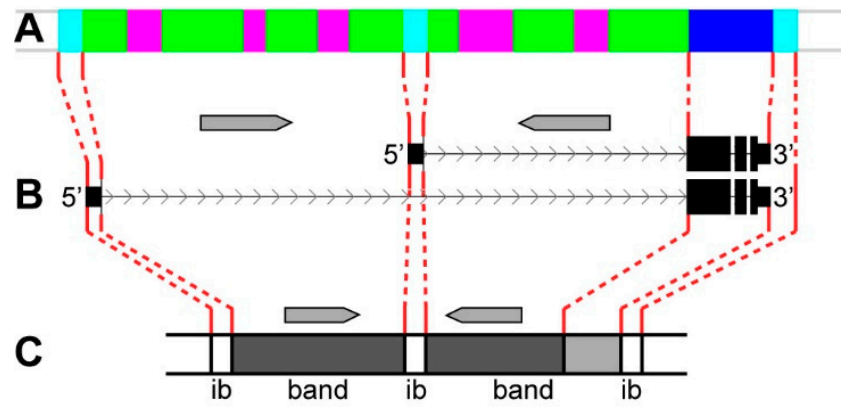

Figure 22. The scheme of the two bands and three interbands formation from the gene material with two introns and two alternative promoters of the predominant long "main" gene; grey arrows represent shorter genes located within the introns of the "main" gene. (A) the four chromatin-state model [39]; (B) exons and introns of the dlg1 gene; and, (C) polytene chromosome bands and interbands (ib) structure comprising genes studied.

The $d n c$ gene is as long as $167.3 \mathrm{~kb}$ and almost $95 \%$ of it accrues to introns (Table 1). The FISH analysis showed that the dnc-I probe (the promoter region of the longest transcript $d n c-R T$ ) is located in the $3 \mathrm{C} 7 / \mathrm{C} 8$ interband; dnc-II probe ( $3^{\prime}$-end of $d n c-R T$ ) is located in 3D1/D2 interband (Figure 13). Thus, according to Bridges' map [25], dnc occupies five bands and six interbands (as this complex region comprises thin and almost indistinguishable bands, we hold on to the number of bands on the map). The dnc-III probe and the second promoter of the $d n c$ gene, respectively, are located in the interband 3C9-10/C11-12 (Figure 13). The region between the dnc-III and dnc-II probes ( $86 \mathrm{~kb}$ in length) is quite homogeneous; it contains two very thin bands 3C11-12 (supposedly represented by intron material) and two loosened large bands 3D1 and 3D2, in which the material of the 3 '-end part of the gene is apparently located. The short genes (like CG14265, ng1, ng3, etc.) that are located within introns of $d n c$ are active predominantly in larval salivary gland cells (see Table S3).

In all of these cases, bands that formed from intron material are mainly characterized by the neutral level of chromatin condensation, malachite coverage (in some cases with ruby and/or lazurite inclusions); on the chromosomes they correspond to grey loose decompacted bands. For example, 3A2-3 band looks black and contains ruby; 3A8-9 band is almost completely decondensed, and chromatin is open for transcription, according to both 4HMM and 3CM models [32,39]. The decompacted chromatin state usually corresponds to a certain level of transcription: in $0 \mathrm{~h}$ prepupa grey bands 1D1-2 (CG43867) and 3A9-10 ( $\mathrm{sgg}$ ) demonstrate high transcriptional activity visualized by ${ }^{3} \mathrm{H}$-uridine incorporation [58]; according to the recent modENCODE data, an active accumulation of RNA pol II is registered in these regions.

The localization of shorter genes within the introns of the predominant long "main" genes is an interesting feature. The data analysis showed that the studied long genes themselves and the shorter genes lying within its introns function in completely different tissues (Table S3). For example, the 
"main" gene CG43867 in the 1D1-2 band is active in an extensive set of tissues on many developmental stages, while the short genes function in a very limited number of cells or organs that are related to male fertility. $E c R$ is a moderately housekeeping gene; two genes affecting male fertility and at least four clusters of transport RNA genes are located within its introns (see other examples in Table S3).

The kirre gene appears to be of particular interest. In polytene chromosomes, this gene has even more complex genetic organization (Figure 23). It is one of the longest genes in the Drosophila genome, as it occupies $393.7 \mathrm{~kb}$ from the promoter (probe kirre-I) to the $3^{\prime}$-end (probe kirre- $\mathrm{V}$ ), and $98.4 \%$ of its length accrues to introns (Table 1). Almost all of material of the gene looks like compact, transcriptionally inactive, and late replicating polytene chromosome bands $[43,56,59,60]$. At chromatin level (Figure 12), this material is also highly compact [35]. Within the introns of kirre 23 other genes are located (Figure 12D, Table S3); some of them demonstrate a moderate level of housekeeping activity, and the rest are developmental genes (Figure 23B,C).

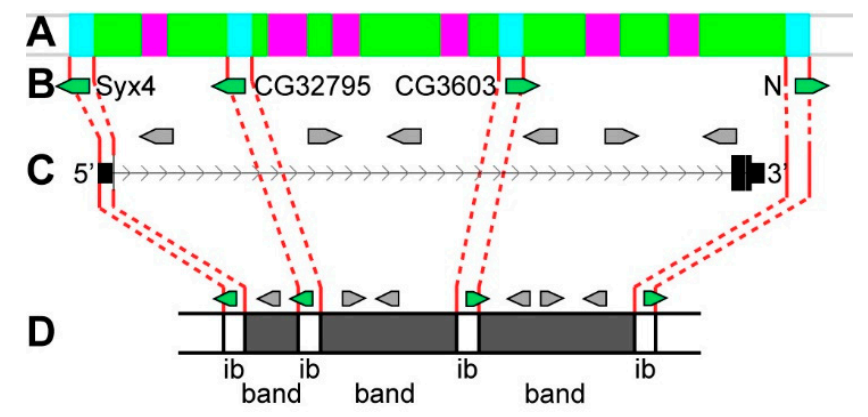

Figure 23. The scheme of the four bands and four interbands formation from the gene material with alternative promoters and three introns composed of late replicated chromatin; grey arrows represent shorter genes located within the introns of the predominant long "main" gene. (A) the four chromatin-state model [39]; (B) moderate level housekeeping genes Syx4, CG32795, CG3603, N; (C) exons and introns of the kirre gene; and, (D) polytene chromosome bands and interbands (ib) structure comprising "main", short development, and housekeeping genes.

Compact material, within which kirre and other short genes are located, is divided by four interbands in locations of kirre-I, kirre-II, kirre-III, and kirre-V probes, where 5'-ends of four housekeeping genes are also localized. Probe kirre-IV is also located in aquamarine, but it was detected on the proximal edge of the 3C5-6 band (Figure 12). The probe kirre-I is localized alongside with the promoter of kirre, whole Syx4 gene, as well as the proteins and genome elements characteristic of interbands which are situated within the $\sim 6.5 \mathrm{~kb}$ aquamarine fragment (corresponds to the $3 \mathrm{~B} 4-5 / \mathrm{C} 1$ interband) (Figure S1). The kirre-II probe is localized in aquamarine fragment (corresponds to the $3 \mathrm{C} 1 / \mathrm{C} 2-3$ interband), where the promoter of the moderately active housekeeping gene CG32795 is also located (Table S3). Similarly, the probe kirre-III is localized in aquamarine fragment (corresponds to 3C2-3/C5-6 interband), where the moderately active whole housekeeping gene CG3603 is situated (Figure S1, Table S3). Finally, the probe kirre-V is localized in aquamarine fragment (corresponds to the $3 \mathrm{C} 5-6 / \mathrm{C} 7$ interband), together with the 3 '-end of kirre and the promoter of the Notch gene (Figure S1) $[61,62]$.

Thus, the locus of the kirre gene contains 23 shorter mostly inactive genes, which, together with kirre, form compact band material. In those housekeeping genes where transcription occurs, the promoters are active and interbands are being formed (Figure 23). Therefore, interbands are formed throughout the length of the extended "main" gene due to the random arrangement of moderately active, but functionally not related, housekeeping genes.

The essential result of this study is the discovery of a novel principle of gene arrangement in polytene chromosomes. In the past, polytene chromosome bands were considered to be sites where only one gene or promoter part and gene body can be located; citologically, they could be found in band/interband, interband/band structure or in a black bands group of functionally not related genes 
(for details, see [19]). The present study shows that genes containing extended introns appear to occupy long chromosome regions composed of band and interband series. The gene material depending on its chromosomal composition is shown to be arranged in two ways: the coding parts of genes are located in grey bands (lazurite chromatin) and intronic material (malachite and ruby chromatin) form bands, which can contain either both exons and introns or intron material only. The promoter regions of such genes are located in aquamarine fragments (interbands) and the gene bodies occupy long DNA sequences, which comprise various chromatin states and different chromosome structures.

It is remarkable that the long genes are involved in ecdysone hormone signalling cascade, which plays the key role during development. These genes demonstrate very complex molecular organization; alternative promoters and exons assemble mRNA from different gene fragments that are active at different developmental stages and demonstrate different genetic significance $[52,53,63,64]$. We might speculate that this genetic complexity might correlate with cytological picture; however, this kind of analysis might be the subject of future studies.

Supplementary Materials: The following are available online at http://www.mdpi.com/2073-4425/11/4/417/s1, Figure S1: Detailed molecular-genetic description for the 3C1-3C7 region. (A) scale and bands localization according to FlyBase; (B) bands (horizontal black bars) and interbands (vertical blue lines) localization according to the present study; (C) genes location (RefSeq); (D) probes location in kirre; (E) chromatin states models (4HMM by [39]; 3CM by [32]; 9stBG3 and 9stS2 by [31] in BG3 and S2 cell lines; 5_chromatin_domains by [30]); (F) localization of RNA polymerase II, GAF and CHRIZ in the S2 cell line (according to modENCODE); (G) localization of SuUR, Lamin and Cohesine in the Kc cell line [30]; (H) replication timing in the S2, Kc and Cl8 cell lines [65]; (I) markers of transcription elongation in different types of cells (according to modENCODE); (J) histone H1 dips in Kc cells [66]; DNA I hypersensitive sites in S2, Kc and BG3 cells [31]; ORC2 in the S2, Kc and BG3 cell lines [67] and in salivary gland [68]., Table S1: Coordinates of the FISH probes used in the present study, Table S2: 70 longest genes characteristics, Table S3: Localization of genes and gene parts in the 15 studied genes in accordance to chromatin states of the 4HMM model and tissues in which they are active (RPKM in parenthesis, FlyBase data).

Author Contributions: Project conceptualization and supervision I.F.Z. and B.E.S.; G.V.P. and V.A.K. performed the in situ experiments; bioinformatics data preparation V.G.L. and V.A.K.; original draft preparation I.F.Z., V.G.L., T.Y.Z., V.A.K.; draft review and editing I.F.Z., V.A.K., E.S.B., O.V.A. All authors have read and approved the final manuscript.

Funding: The present study was supported by the Russian Science Foundation on the project \#19-14-00051 in fluorescent in situ hybridization; by the Fundamental Scientific Research Program on the projects \#0310-2019-0003 and \#19-44-543017\19 in chromatin states data analysis; by the Fundamental Scientific Research Program on the project \#0324-2019-0040-C-01 in bioinformatic study of gene introns and transcripts.

Acknowledgments: We thank Olga V. Demakova and Lidiya V. Boldyreva at IMCB SB RAS for kindly providing us with primers for the Nrg-103 probe.

Conflicts of Interest: The authors declare no conflict of interest.

\section{References}

1. Koltzoff, N. The structure of the chromosomes in the salivary glands of Drosophila. Science 1934, 80, 312-313. [CrossRef] [PubMed]

2. Mackensen, O. Locating genes on the salivary chromosomes. Cytogenetic methods demonstrated in determining position of genes on the X-chromosome of Drosophila melanogaster. J. Hered. 1935, 26, 163-174. [CrossRef]

3. Muller, H.J.; Prokofyeva, A.A. The individual gene in relation to the chromomere and the chromosome. Proc. Natl. Acad. Sci. USA 1935, 21, 16-26. [CrossRef]

4. Bridges, C.B. Salivary chromosome maps: With a key to the banding of the chromosomes of Drosophila melanogaster. J. Hered. 1935, 26, 60-64. [CrossRef]

5. Muller, H.J. On the dimensions of chromosomes and genes in Drosophila salivary glands. Am. Nat. 1935, 69, 405-411. [CrossRef]

6. Prokofyeva-Belgovskaya, A.A. The structure of the chromocenter. Cytologia 1935, 6, 438-443. [CrossRef]

7. Metz, C.W. Effects of mechanical distortion on the structure of salivary gland chromosomes. Biol. Bull. 1936, 71, 238-248. [CrossRef]

8. Animal Cytology and Evolution, 2nd ed.; Cambridge University Press: Cambridge, UK, 1954.

9. Bauer, H.; Beermann, W. Polytenia of giant chromosomes. Chromosoma 1952, 4, 830-848. 
10. Beermann, W. Chromomore constancy and specific modifications of the chromosome structure in development and organ differentiation of Chironomus tentans. Chromosoma 1952, 5, 139-198. [CrossRef]

11. Beermann, W. Nuclear differentiation and functional morphology of chromosomes. Cold Spring Harb. Symp. Quant. Biol. 1956, 21, 217-232. [CrossRef]

12. Mechelke, F. Reversible structural modifications of the chromosomes in salivary glands of Acricotopus lucidus. Chromosoma 1953, 5, 511-543. [CrossRef] [PubMed]

13. Breuer, M.E.; Pavan, C. Behavior of polytene chromosomes of Rhynchosciara angelae at different stages of larval development. Chromosoma 1955, 7, 341-386. [CrossRef] [PubMed]

14. Beermann, W. Structure and function of interphase chromosomes. In Genetics Today: XI International Congress of Genetics; Pergamon Press: Oxford, UK; London, UK; Edinburgh, Scotland; New York, NY, USA; Paris, France; Frankfurt, Germany, 1965; Volume 2, pp. 375-384.

15. Beermann, W. Gene action at the level of the chromosome. In Heritage from Mendel; The University of Wisconsin Press: Madison, WI, USA; London, UK, 1967; pp. 179-201.

16. Rudkin, G.T. The relative mutabilities of DNA in regions of the $\mathrm{X}$ chromosome of Drosophila melanogaster. Genetics 1965, 52, 665-681. [PubMed]

17. Olenov, I.M. Genome organization in Metazoa. Tsitologiya 1974, 16, 403-419.

18. Judd, B.H.; Shen, M.W.; Kaufman, T.C. The anatomy and function of a segment of the X chromosome of Drosophila melanogaster. Genetics 1972, 71, 139-156.

19. Zhimulev, I.F. Genetic Organization of Polytene Chromosomes, 1st ed.; Academic Press: Cambridge, MA, USA, 1999; Volume 39, ISBN 0-12-017639-4.

20. Crick, F. General model for the chromosomes of higher organisms. Nature 1971, 234, 25-27. [CrossRef]

21. Paul, J. General theory of chromosome structure and gene activation in eukaryotes. Nature 1972, 238, 444-446. [CrossRef]

22. Sorsa, V. Electron microscopic mapping and ultrastructure of Drosophila polytene chromosomes. In Insect Ultrastructure: Volume 2; King, R.C., Akai, H., Eds.; Springer US: Boston, MA, USA, 1984; pp. 75-107. ISBN 978-1-4613-2715-8.

23. Speiser, C. A hypothesis on the functional organization of the chromosomes of higher organisms. Theor. Appl. Genet. 1974, 44, 97-99. [CrossRef]

24. Zhimulev, I.F.; Belyaeva, E.S. Proposals to the problem of structural and functional organization of polytene chromosomes. Theor. Appl. Genet. 1974, 45, 335-340. [CrossRef]

25. Bridges, C.B. A revised map of the salivary gland X-chromosome of Drosophila melanogaster. J. Hered. 1938, 29, 11-13. [CrossRef]

26. Kozlova, T.Y.; Semeshin, V.F.; Tretyakova, I.V.; Kokoza, E.B.; Pirrotta, V.; Grafodatskaya, V.E.; Belyaeva, E.S.; Zhimulev, I.F. Molecular and cytogenetical characterization of the 10A1-2 band and adjoining region in the Drosophila melanogaster polytene X chromosome. Genetics 1994, 136, 1063-1073. [PubMed]

27. Vatolina, T.Y.; Boldyreva, L.V.; Demakova, O.V.; Demakov, S.A.; Kokoza, E.B.; Semeshin, V.F.; Babenko, V.N.; Goncharov, F.P.; Belyaeva, E.S.; Zhimulev, I.F. Identical functional organization of nonpolytene and polytene chromosomes in Drosophila melanogaster. PLoS ONE 2011, 6, e25960. [CrossRef]

28. Adams, M.D.; Celniker, S.E.; Holt, R.A.; Evans, C.A.; Gocayne, J.D.; Amanatides, P.G.; Scherer, S.E.; Li, P.W.; Hoskins, R.A.; Galle, R.F.; et al. The genome sequence of Drosophila melanogaster. Science 2000, 287, 2185-2195. [CrossRef] [PubMed]

29. modENCODE Consortium; Roy, S.; Ernst, J.; Kharchenko, P.V.; Kheradpour, P.; Negre, N.; Eaton, M.L.; Landolin, J.M.; Bristow, C.A.; Ma, L.; et al. Identification of functional elements and regulatory circuits by Drosophila modENCODE. Science 2010, 330, 1787-1797. [PubMed]

30. Filion, G.J.; van Bemmel, J.G.; Braunschweig, U.; Talhout, W.; Kind, J.; Ward, L.D.; Brugman, W.; de Castro, I.J.; Kerkhoven, R.M.; Bussemaker, H.J.; et al. Systematic protein location mapping reveals five principal chromatin types in Drosophila cells. Cell 2010, 143, 212-224. [CrossRef] [PubMed]

31. Kharchenko, P.V.; Alekseyenko, A.A.; Schwartz, Y.B.; Minoda, A.; Riddle, N.C.; Ernst, J.; Sabo, P.J.; Larschan, E.; Gorchakov, A.A.; Gu, T.; et al. Comprehensive analysis of the chromatin landscape in Drosophila melanogaster. Nature 2011, 471, 480-485. [CrossRef] [PubMed]

32. Milon, B.; Sun, Y.; Chang, W.; Creasy, T.; Mahurkar, A.; Shetty, A.; Nurminsky, D.; Nurminskaya, M. Map of open and closed chromatin domains in Drosophila genome. BMC Genom. 2014, 15, 988. [CrossRef] 
33. Demakova, O.V.; Demakov, S.A.; Boldyreva, L.V.; Zykova, T.Y.; Levitsky, V.G.; Semeshin, V.F.; Pokholkova, G.V.; Sidorenko, D.S.; Goncharov, F.P.; Belyaeva, E.S.; et al. Faint gray bands in Drosophila melanogaster polytene chromosomes are formed by coding sequences of housekeeping genes. Chromosoma 2019, 129, 25-44. [CrossRef]

34. Sidorenko, D.S.; Sidorenko, I.A.; Zykova, T.Y.; Goncharov, F.P.; Larsson, J.; Zhimulev, I.F. Molecular and genetic organization of bands and interbands in the dot chromosome of Drosophila melanogaster. Chromosoma 2019, 128, 97-117. [CrossRef]

35. Semeshin, V.F.; Demakov, S.A.; Zhimulev, I.F. Characteristics of structures of Drosophila polytene chromosomes formed by transposable DNA fragments. Genetika 1989, 25, 1968-1978.

36. Demakov, S.A.; Vatolina, T.Y.; Babenko, V.N.; Semeshin, V.F.; Belyaeva, E.S.; Zhimulev, I.F. Protein composition of interband regions in polytene and cell line chromosomes of Drosophila melanogaster. BMC Genom. 2011, 12, 566. [CrossRef] [PubMed]

37. Zhimulev, I.F.; Belyaeva, E.S.; Vatolina, T.Y.; Demakov, S.A. Banding patterns in Drosophila melanogaster polytene chromosomes correlate with DNA-binding protein occupancy. Bioessays 2012, 34, 498-508. [CrossRef] [PubMed]

38. Boldyreva, L.V.; Goncharov, F.P.; Demakova, O.V.; Zykova, T.Y.; Levitsky, V.G.; Kolesnikov, N.N.; Pindyurin, A.V.; Semeshin, V.F.; Zhimulev, I.F. Protein and genetic composition of four chromatin types in Drosophila melanogaster cell lines. Curr. Genom. 2017, 18, 214-226. [CrossRef] [PubMed]

39. Zhimulev, I.F.; Zykova, T.Y.; Goncharov, F.P.; Khoroshko, V.A.; Demakova, O.V.; Semeshin, V.F.; Pokholkova, G.V.; Boldyreva, L.V.; Demidova, D.S.; Babenko, V.N.; et al. Genetic organization of interphase chromosome bands and interbands in Drosophila melanogaster. PLoS ONE 2014, 9, e101631. [CrossRef] [PubMed]

40. Zykova, T.Y.; Levitsky, V.G.; Belyaeva, E.S.; Zhimulev, I.F. Polytene chromosomes-A portrait of functional organization of the Drosophila genome. Curr. Genom. 2018, 19, 179-191. [CrossRef] [PubMed]

41. Zykova, T.Y.; Popova, O.O.; Khoroshko, V.A.; Levitsky, V.G.; Lavrov, S.A.; Zhimulev, I.F. Genetic organization of open chromatin domains situated in polytene chromosome interbands in Drosophila. Dokl. Biochem. Biophys. 2018, 483, 297-301. [CrossRef] [PubMed]

42. Khoroshko, V.A.; Levitsky, V.G.; Zykova, T.Y.; Antonenko, O.V.; Belyaeva, E.S.; Zhimulev, I.F. Chromatin heterogeneity and distribution of regulatory elements in the late-replicating intercalary heterochromatin domains of Drosophila melanogaster chromosomes. PLoS ONE 2016, 11, e0157147. [CrossRef]

43. Beermann, W. Chromomeres and genes. Results Probl. Cell Differ. 1972, 4, 1-33.

44. Semeshin, V.F.; Demakov, S.A.; Perez Alonso, M.; Belyaeva, E.S.; Bonner, J.J.; Zhimulev, I.F. Electron microscopical analysis of Drosophila polytene chromosomes. V. Characteristics of structures formed by transposed DNA segments of mobile elements. Chromosoma 1989, 97, 396-412. [CrossRef]

45. Khoroshko, V.A.; Pokholkova, G.V.; Zykova, T.Y.; Osadchiy, I.S.; Zhimulev, I.F. Gene dunce localization in the polytene chromosome of Drosophila melanogaster long span batch of adjacent chromosomal structures. Dokl. Biochem. Biophys. 2019, 484, 55-58. [CrossRef]

46. Zhimulev, I.F.; Boldyreva, L.V.; Demakova, O.V.; Poholkova, G.V.; Khoroshko, V.A.; Zykova, T.Y.; Lavrov, S.A.; Belyaeva, E.S. Drosophila polytene chromosome bands formed by gene introns. Dokl. Biochem. Biophys. 2016, 466, 57-60. [CrossRef] [PubMed]

47. Semeshin, V.F.; Belyaeva, E.S.; Shloma, V.V.; Zhimulev, I.F. Electron microscopy of polytene chromosomes. Methods Mol. Biol. 2004, 247, 305-324. [PubMed]

48. Ashburner, M.; Golic, K.G.; Hawley, R.S. Drosophila: A Laboratory Handbook, 2nd ed.; Cold Spring Harbor Laboratory Press: Cold Spring Harbor, NY, USA, 2005; ISBN 0-87969-706-7.

49. Machyna, M.; Kiefer, L.; Simon, M.D. Enhanced nucleotide chemistry and toehold nanotechnology reveals lncRNA spreading on chromatin. Nat. Struct. Mol. Biol. 2020, 27, 297-304. [CrossRef] [PubMed]

50. Belyaeva, E.S.; Vlassova, I.E.; Biyasheva, Z.M.; Kakpakov, V.T.; Richards, G.; Zhimulev, I.F. Cytogenetic analysis of the 2B3-4-2B11 region of the $\mathrm{X}$ chromosome of Drosophila melanogaster. II. Changes in 20-OH ecdysone puffing caused by genetic defects of puff 2B5. Chromosoma 1981, 84, 207-219. [CrossRef] [PubMed]

51. Belyaeva, E.S.; Protopopov, M.O.; Baricheva, E.M.; Semeshin, V.F.; Izquierdo, M.L.; Zhimulev, I.F. Cytogenetic analysis of region 2B3-4-2B11 of the X-chromosome of Drosophila melanogaster. VI. Molecular and cytological mapping the ecs locus and the 2B puff. Chromosoma 1987, 95, 295-310. [CrossRef] 
52. DiBello, P.R.; Withers, D.A.; Bayer, C.A.; Fristrom, J.W.; Guild, G.M. The Drosophila Broad-Complex encodes a family of related proteins containing zinc fingers. Genetics 1991, 129, 385-397.

53. Bayer, C.A.; Holley, B.; Fristrom, J.W. A switch in Broad-Complex zinc-finger isoform expression is regulated posttranscriptionally during the metamorphosis of Drosophila imaginal discs. Dev. Biol. 1996, 177, 1-14. [CrossRef]

54. Belyaeva, E.S.; Zhimulev, I.F. Cytogenetic analysis of the X-chromosome region 2B3-4-2B11 of Drosophila melanogaster. IV. Mutation at the swi (singed wings) locus interfering with the late 20-OH ecdysone puff system. Chromosoma 1982, 86, 251-263. [CrossRef]

55. Bridges, C.B.; Bridges, P.N. A new map of the second chromosome: A revised map of the right limb of the second chromosome of Drosophila melanogaster. J. Hered. 1939, 30, 475-476. [CrossRef]

56. Semeshin, V.F.; Baricheva, E.M.; Belyaeva, E.S.; Zhimulev, I.F. Electron microscopical analysis of Drosophila polytene chromosomes. II. Development of complex puffs. Chromosoma 1985, 91, 210-233. [CrossRef]

57. Bridges, P.N. A revised map of the left limb of the third chromosome of Drosophila melanogaster. J. Hered. 1941, 32, 64-65. [CrossRef]

58. Zhimulev, I.F.; Belyaeva, E.S. 3H-Uridine labelling patterns in the Drosophila melanogaster salivary gland chromosomes X, 2R and 3L. Chromosoma 1975, 49, 219-231. [CrossRef]

59. Arcos-Terán, L. DNA replication and the nature of late replicating loci in the X-chromosome of Drosophila melanogaster. Chromosoma 1972, 37, 233-296. [CrossRef] [PubMed]

60. Zhimulev, I.F.; Belyaeva, E.S.; Makunin, I.V.; Pirrotta, V.; Volkova, E.I.; Alekseyenko, A.A.; Andreyeva, E.N.; Makarevich, G.F.; Boldyreva, L.V.; Nanayev, R.A.; et al. Influence of the SuUR gene on intercalary heterochromatin in Drosophila melanogaster polytene chromosomes. Chromosoma 2003,111,377-398. [CrossRef] [PubMed]

61. Rykowski, M.C.; Parmelee, S.J.; Agard, D.A.; Sedat, J.W. Precise determination of the molecular limits of a polytene chromosome band: Regulatory sequences for the Notch gene are in the interband. Cell 1988, 54, 461-472. [CrossRef]

62. Volkova, E.I.; Andreyenkova, N.G.; Andreyenkov, O.V.; Sidorenko, D.S.; Zhimulev, I.F.; Demakov, S.A. Structural and functional dissection of the $5^{\prime}$ region of the Notch gene in Drosophila melanogaster. Genes (Basel) 2019, 10, 1037. [CrossRef]

63. White, K.P.; Hurban, P.; Watanabe, T.; Hogness, D.S. Coordination of Drosophila metamorphosis by two ecdysone-induced nuclear receptors. Science 1997, 276, 114-117. [CrossRef]

64. Bender, M.; Imam, F.B.; Talbot, W.S.; Ganetzky, B.; Hogness, D.S. Drosophila ecdysone receptor mutations reveal functional differences among receptor isoforms. Cell 1997, 91, 777-788. [CrossRef]

65. Schwaiger, M.; Stadler, M.B.; Bell, O.; Kohler, H.; Oakeley, E.J.; Schübeler, D. Chromatin state marks cell-typeand gender-specific replication of the Drosophila genome. Genes Dev. 2009, 23, 589-601. [CrossRef]

66. Braunschweig, U.; Hogan, G.J.; Pagie, L.; van Steensel, B. Histone H1 binding is inhibited by histone variant H3. 3. EMBO J. 2009, 28, 3635-3645. [CrossRef]

67. Eaton, M.L.; Prinz, J.A.; MacAlpine, H.K.; Tretyakov, G.; Kharchenko, P.V.; MacAlpine, D.M. Chromatin signatures of the Drosophila replication program. Genome Res. 2011, 21, 164-174. [CrossRef] [PubMed]

68. Sher, N.; Bell, G.W.; Li, S.; Nordman, J.; Eng, T.; Eaton, M.L.; MacAlpine, D.M.; Orr-Weaver, T.L. Developmental control of gene copy number by repression of replication initiation and fork progression. Genome Res. 2012, 22, 64-75. [CrossRef] [PubMed]

(C) 2020 by the authors. Licensee MDPI, Basel, Switzerland. This article is an open access article distributed under the terms and conditions of the Creative Commons Attribution (CC BY) license (http://creativecommons.org/licenses/by/4.0/). 